\title{
From Vecten's Theorem to Gamow's Problem: Building an Empirical Classification Model for Sequential Instructional Problems in Geometry
}

\author{
Dr. Stavroula Patsiomitou* \\ Ph.D. (University of Ioannina), \\ MEd, Department of Mathematics, National and Kapodistrian University of Athens, Greece \\ E-mail: spatsiom@gmail.com
}

\begin{abstract}
In the current study, I will be presenting a literature review regarding the importance of students building a problem's representation and the role modeling a real-world problem plays in students' progressive mathematization. I shall introduce five types of geometrical problems applying the meaning of Linking Visual Active Representations (LVARs). Concrete examples will be presented in the next sections (i.e., Euclid's proof of the Pythagorean Theorem, Vecten's theorem, Gamow's problem). I shall also introduce the meanings of hybrid object and diagram, as well as the meaning of dynamic section in a dynamic geometry environment, through examples. To summarize, I created an empirical classification model of sequential instructional problems in geometry. Its contribution to our knowledge in the area of the didactics of mathematics lies in the fact that this sequence of problems is regarded as a process whereby students develop a sequentially deeper understanding and increasingly more coherent reasoning that raises their van Hiele level.

Keywords: dynamic section, hybrid object, Euclid "Elements", Pythagorean Theorem, Vecten's Theorem, Gamow's problem, problem-solving.
\end{abstract}

DOI: $10.7176 / \mathrm{JEP} / 10-5-01$

1. Introduction: Defining problem and problem solving in mathematics education

The word "problem" is derived from the Greek word "provlema" with etymology from the verb "provalein", whose meaning covers "projecting, showing, revealing, displaying, presenting": i.e. 'provalein' refers to a goal presented in a question. (See also, https://etymonline.com).

The word "problem" is defined as:

- "[...] An inquiry starting from given conditions to investigate or demonstrate a fact, result, or law". (https://en.oxforddictionaries.com)

- “[...] Something that causes difficulty [...and especially a mathematics problem] is a question to be answered or solved by reasoning or calculations". (https:// dictionary. cambridge.org).

- “[...] A question raised for inquiry, consideration or solution". (https://www.merriam-webster.com).

Charles \& Lester (1982) define a problem as a task for which "the person confronting it wants or needs to find a solution, has no readily available procedure for finding the solution and must make an attempt to find a solution." (Charles \& Lester, 1982, p. 5, in Nunokawa \& Fukuzawa, 2002). The definition of the word problem especially in mathematics or physics has to do with a proposition or an inquiry stating something to be proved. In order to answer this inquiry we must combine data and information, and then we can derive a solution following logical inferences and deductive reasoning. In my opinion, mathematical problem solving is a process with the following prerequisites: (a) 'input' in the form of the verbal description of a mathematical problem which includes general information, (b) 'input' in the form of mathematical statements that constitute the problems' hypotheses, (c) 'a goal' expressed in a statement (d) concrete preexisting knowledge (i.e. axioms, theorems, proofs, concepts, definitions, formulas and methods) and appropriate heuristic skills (e) appropriate logical inferences and reasoning (e.g., deductive, inductive, abductive, transformational). According to Mayer (1983) a problem consists of givens, goals and obstacles, as described in the following figure 1. The problem solving process derives abstractions and infers consequences and other findings from input data and information to produce a solution that addresses the task and leads to a sumperasma (another Greek word whose meaning encompasses both "a logical conclusion" and "a summary in a few words"). 


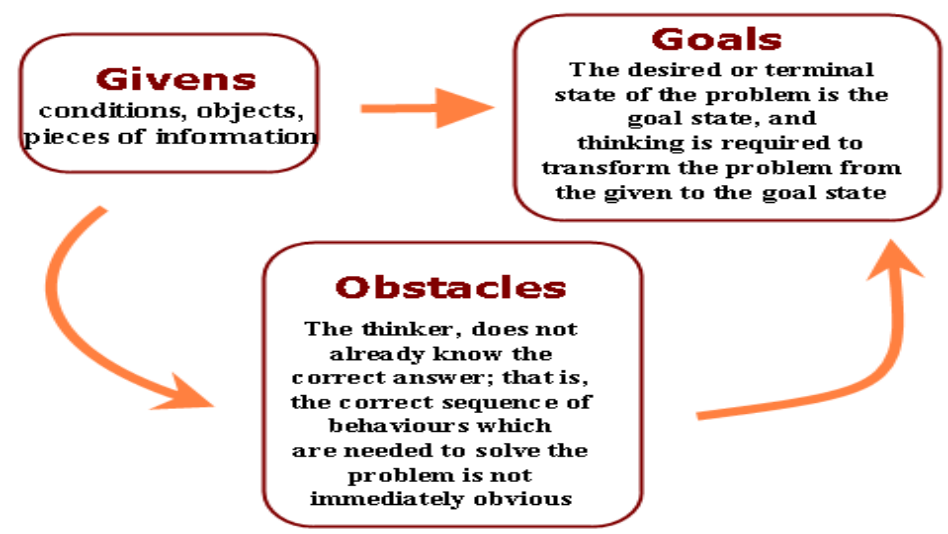

Fig. 1. Defining problem (Mayer, 1983, p.4 in Stoyanova, 1997, p.2): an adaptation for the current study

Aamodt (1991) also states that "A mathematical problem may be structured [or divided] in sub-problems, in which case the problem solving process may be correspondingly split into sub-processes" (Aamodt, 1991, p.31). As a teacher of mathematics, I have often asked myself the following questions:

- Are students able to build a reasonable and meaningful representation of a problem by means of a conscious and intentional process?

- Do students connect the process of representing the problem with preexisting knowledge that can be brought to bear on the problem?

- $\quad$ During the problem-solving process, do students demonstrate significant, meaningful and appropriately organized connections between pieces of information in their statement of the problem?

- Do students construct a logical correspondence between the structure of the verbal expression of the problem and the structure of its solution?

- Can we identify different levels of investigation in problem-solving in order to enhance the abstract thinking of our students?

- What conceptual considerations need to be taken into account when designing problems in a dynamic geometry environment? How do these conceptual considerations impact on our students' learning and understanding of mathematics?

In the sections that follow, I will be presenting a literature review regarding the importance of students building a problem's representation, the role modeling a real-world problem plays in students' gradual investigation of a problem, and the classification of sequential instructional problems. Concretely:

- Building on earlier works (e.g., Patsiomitou, 2008a, b) I shall review the building of sequential dynamic diagrams of the problem in "The Geometer's Sketchpad" (henceforth Sketchpad) (Jackiw, 1988) dynamic geometry software, applying the meaning of Linking Visual Active Representations (LVARs) (e.g., Patsiomitou, 2008 a, b, c, d, 2009 a, b, 2010, 2011, 2012a, b, 2013, 2014, 2018a, b), to 'dynamically' scaffold students thinking. I shall present two examples: (a) Euclid's proof of the Pythagorean Theorem, known as Proposition 47, in Euclid "Elements", Book I (i.e., Euclid's proof of I.47) using LVARs, mode 3; Proposition 4 in Book I of Euclid "Elements" regarding the congruence of triangles will also be instrumentally decoded in Sketchpad, as it is a valuable element in the proving process for many problems. (b) a few sub-problems of 'The Vecten's theorem' (reported in "Jesuit Geometry", a translation in Greek, p.774, published in Annales De Gergonne, 1816, vol.VII, p.322).

- I shall explain what I mean by the phrase "a hybrid-parametrical version" of Vecten's theorem and how I created this parametrical version (Patsiomitou, 2006, p.1270-1273, in Greek) using algebraic parameters for geometry in Sketchpad.

- I shall investigate the importance of the modeling process for students' understanding and for the development of their progressive mathematization abilities; modeling is especially important for students who struggle with real-world geometric problem. I will be focusing on a non-routine realworld open problem [Gamow's problem (1948/1988)] which combines investigation, discovery, knowledge and deductive argumentation. The problem will be addressed in Sketchpad environment. Moreover, I shall explain how a problem can be made more interesting by including a visual demonstration with LVARs and the importance of LVARs, as scaffolding for the students as they develop their proving abilities. For this, I shall illustrate how I designed LVAR modes, (e.g., Patsiomitou, 2008a, b), creating a bridge between a formal theorem and an open problem and thus transforming a formal theorem into a DGS 'game' with a view to reducing the complexity of the problem and increasing the students ability to formulate deductive argumentation. 
My work with students at the secondary and tertiary levels leads me to identify five types of geometrical problems:

- Dynamic geometrical problems with non-given answers (abbreviated as DGNA) which the students investigate in a DGS environment using linking visual active representations (LVARs) (e.g., Patsiomitou, 2008a, b, 2012a, b). Such problems improve motivation and creativity through the use of "why" challenges and "what if" strategies; provoke students' reflecting visual reaction (RVR) (e.g., Patsiomitou, 2008a, b, 2012a, b), by requiring them to employ preexisting theoretical knowledge, perceptual skills, and deductive argumentation.

- Dynamic geometrical problems with given answers (abbreviated as DGGA) which the students investigate and prove in a DGS environment. Such problems motivate students to create theoretical relationship between information and data which is explicitly provided; to translate this information and data from one form of representation to another and to employ their preexisting theoretical knowledge and deductive reasoning skills.

- Dynamic geometrical problems modeled in a DGS with hybrid-dynamic geometrical representations (Patsiomitou, 2018b, p.42) with non-given answers (abbreviated as HGNA) which the students investigate in a DGS environment. Such problems require the students to interact with a sophisticated level of information and data which is explicitly provided in the DGS environment and to employ advanced theoretical knowledge and abstract thinking.

- Real world geometrical problems with non-given answers (abbreviated as RGNA) which students investigate in a dynamic or static environment. Such problems relate to 'dynamic' methods in geometry and require students to 'think in motion' in the environment, employing higher order thinking and organizing phenomena by means of progressive mathematization. The benefit of working with real problems in a DGS incorporates the combination of transformations using LVARs.

- Static geometrical problems with given answers (abbreviated as SGGA) which students solve in a paper-pencil environment. Such problems contain certain information and questions which require students to apply their theoretical knowledge and perceive the structure of the problem and the principles and concepts that could be used to solve it.

Summarizing, I would like to present five investigational levels of a problem solving process, synthesizing, elaborating on and addressing conceptual and procedural understanding through feedback provided at every intermediate step in the problem's solution which is designed in the light of the cognitive processes elicited at each level. My aim is to construct a didactic sequence in which the next problem will become the next level in the development of the students' reasoning. The emerging theoretical construct provides both a methodology for building up the problem-solving process and an approach to addressing difficulties students face in learning geometrical concepts, which uses anticipatory thought experiments in which we envision how we can construct an organizational structure and a learning trajectory through problem solving as the students engage with the process.

\section{Geometry between the abstract and the visual}

Freudenthal (1971) in his article "Geometry between the devil and the deep sea" responding to his own questions, writes:

"[...] the first piece of education in history we know about, is a lesson of geometry, the Socratic lesson Menon's slave was taught on doubling the square. Socrates taught the slave not the solution of the problem nor solving the problem, but finding the solution by trial and error. He did not teach a readymade solution but the way of reinventing the solution. Two millenia later Comenius said: 'The best way to teach an activity is to show it.'[...]'(p. 414).

This piece of knowledge made me consider a mixed method which my students could use to solve a problem; such a method would require me to design a way for the students to reinvent the solution or discover it using a trial and error method. From a lack of competence my students (13-14 years-old) to composing geometric shapes the "guided" reinvention of doubling the square mentioned in the Socratic lesson, stimulated the use of materials -digital or not- in my class, with which my students could support their reasoning by transforming the shapes, using a trial and error method. The following discussion is one I have with my high school students almost every year in class (Fig.2):

Researcher: How can you double the area of the square?

Students: We can double the sides of the square!

Researcher: Use this dot paper and construct the new square.

Students: Oh! It is not correct! The square is quadrupled. We have constructed 4 equal squares with the small square.

Researcher: Now, can you find a solution to the problem? 
Students: If we construct the diagonals of the quadrupled square, the new figure inside is also a square ..... and it is the double square of the initial square.

Researcher: Can you answer why that happens?

Students: Its sides are congruent and perpendicular to each other.

Researcher: Can you prove that the new square has double area of the initial square?

Only a few students had the competence to answer the last question. This was difficult for them, as they did not have the competence to transform the right and isosceles triangle in their mind; in other words, they could not generate mental transformations. Many students do not have the ability to dynamically visualize and mentally manipulate geometric objects, which is an important skill for solving problems in geometry. Without it, they cannot reflect on or anticipate a possible solution to the problem. Moreover, according to the van Hiele theory (Fuys et al., 1984) students are not able to formulate deductive argumentations as this kind of argumentation occurs when the students have developed their thinking. Freudenthal (1971) supports that

"In which order, if not in a deductive one, should mathematics be taught? The answer is simple: in that one in which it can be learned, which means, the order in which it could be invented by the student. This is not at all a revolutionary idea. It is the Socratic lesson. In a thought experiment the teacher has been reinventing the subject matter as though he himself was the student, and this is what he teaches. [...] This is a modern reinforcement of the socratic idea" (p.416).
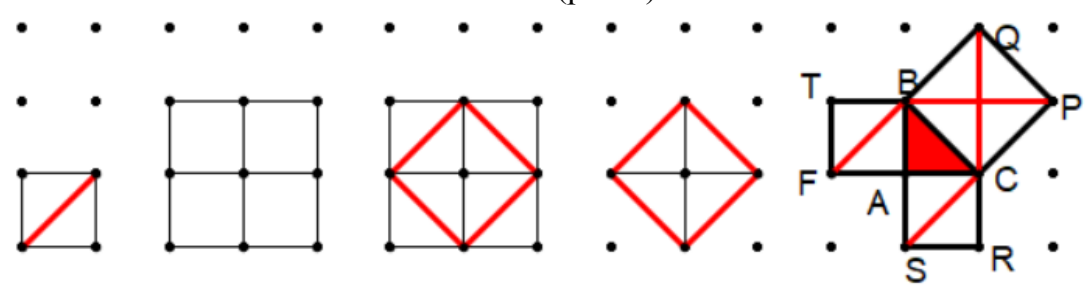

Fig. 2. Transforming the shapes using a mixed 'trial and error' and 'guided reinvention" method in my class.

The teachers' task is to design a course "of action that fits anticipated student reactions. More precisely, the idea is that teaching matter is re-invented by students in such interaction" (Gravemeijer \& Terwel, 2000, p.786). Dina van Hiele's (Fuys et al, 1984, p. 207) thesis was an "inquiry into the didactic possibilities of geometrical instruction in a class where the child is given concrete material in a systematic way so as to unfold visual thinking and to transform it in the abstract way of thought which the logical system of geometry demands". Dina van Hiele argues that "the teacher of mathematics should help his/her pupils to transform the structures, produced in their visual field of observation, into geometrical structure" (p. 245). With regard to the problem mentioned above, firstly, I usually ask my students to experiment using transformations (e,g,. a dot.gsp file or a squared paper) this will help them understand that if they double the side of the square, the area of the square this creates is quadrupled. (Fig. 2). Freudenthal (1971) supports that

"[...] transformations in geometry were long ago advocated by F. Klein as a consequence of his so-called Erlanger Programm. The breakthrough of transformations in geometry is of a rather recent date. How to explain this delay, [...], where Klein had been the venerated master of a generation of teachers ?". [Moreover], "there is not any textbook based on the transformation idea" (p. 433).

Generally speaking, geometric figures or diagrams constitute a unique framework for communicating mathematical ideas, very important for students' development of thinking, especially when technology is incorporated to their construction. The use of material figures helped my students gain competence in composing geometric shapes, initially through trial and error and then purposefully find that four congruent isosceles and right triangles can be composed into a square and, ultimately, to intentionally synthesize combinations of shapes into new shapes with a view to reinventing a rule or a theorem. This concrete experimentation on the part of my students is also an excellent mean of incorporating worthwhile ideas and introducing theorems and definitions into my lessons (for example, the Pythagorean Theorem and irrational numbers).

"Pythagoras noticed that, if $\mathrm{a}=1$ and $\mathrm{b}=1$, then $\mathrm{c}^{2}=2$. He wondered whether there was a rational number $\mathrm{c}$ that satisfied this last identity. His stunning conclusion was this theorem: There is no rational number c such that $\mathrm{c}^{2}=2$ " (Krantz, 2007, p.11)

Learning through problem solving can be addressed by both open-ended complex geometric problems and non-open strict geometric problems. In order to distinguish open from non-open problems, I will quote the following example from my introduction to the Pythagorean Theorem: 
\begin{tabular}{|l|l|}
\hline Non-open problem & Open problem \\
\hline
\end{tabular}

Given a right triangle $\quad$ a) If the area of the square TBAB is equal to $1 \mathrm{~cm} 2$, can you calculate the prove that (a) $\mathrm{a}^{2}=\mathrm{b}^{2}+\mathrm{c}^{2}$

( $a$ is the hypotenuse of the right triangle) and (b) the concrete relation (Pythagorean theorem) characterizes only rightangled triangles. areas of the squares constructed outside the triangle ABC (Fig. 2). What do you observe? Repeat your experiments doubling the side of the square TBAB in your dot paper and write down the new results. Continue and formulate a rule for this situation.

b) Consider the squares constructed externally on the sides a, b, c of a right triangle. If $\mathrm{a}=5 \mathrm{~cm}, \mathrm{~b}=3 \mathrm{~cm}, \mathrm{c}=4 \mathrm{~cm}$ can you calculate the areas of the squares? Calculate $a^{2}$, then $b^{2}+c^{2}$. What do you observe? Does this occur to every right triangle? Can you formulate a rule for this phenomenon? Does this rule holds true for all right triangle regardless of the lengths of their sides? Does this Pythagorean relation characterize only right-angled triangles?

Students must be encouraged to solve their own problems that mirror real life situations. The open problem can be solved using different approaches and in multiple ways, encourages and stimulates discovery, prompts students to generate conjunctures and most students can get involved as Arsac et al. (1988) mention: "The statement of the problem [...] fosters discovery [...]. creates a situation stimulating the production of conjectures.[...]" (Arsac, Germain \& Mante, 1988 in Furinghetti \& Paola, 2003, p.398).

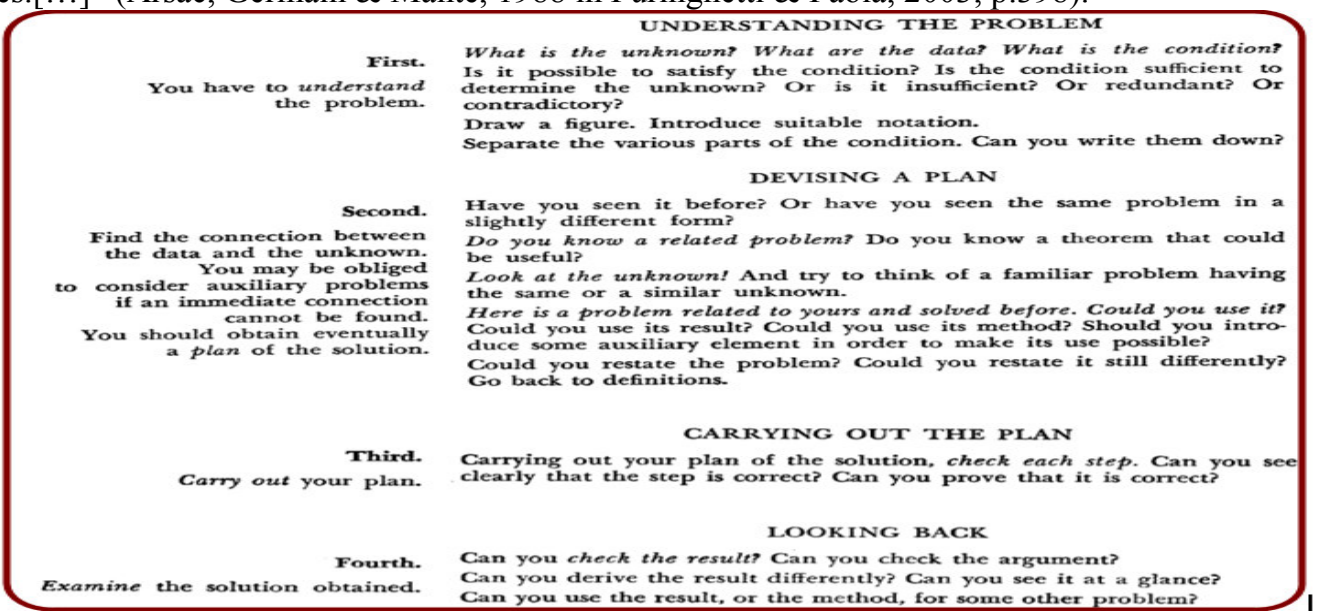

Fig. 3. The four problem-solving phases (Polya, 1957): an excerpt from the manuscript (see website [1])

The solution to an open problem cannot be reduced to a routine problem that requires a technique the student has probably memorized; instead it provides the student with the freedom to generate conjectures. Conjectures are the first step for the students to formulate logical inferences and then deductive argumentation, depended on their level of understanding. In his book "How to Solve It", Polya (1957/1966) based on his experience as a teacher of mathematics suggested four problem-solving phases, pointing out the cognitive actions linked to the process of problem-solving (Fig. 3). George Pólya's (1966) addressed also the difference between "tasks" and "mathematical problems". He also distinguished routine from non-routine problems, from a teacher's point of view. As he supports:

"[...] The nonroutine problem demands some degree of creativity and originality from the student, the routine problem does not. [...] I shall not explain what is a nonroutine mathematical problem: If you have never solved one, if you have never experienced the tension and triumph of discovery, and if, after some years of teaching, you have not yet observed such tension and triumph in one of your students, look for another job and stop teaching mathematics". (Pólya, 1966, pp. 126-127, reported in Szabo, 2017, p.40)

\section{Building a representation during problem solving process}

A word-problem (or an oral mathematical problem) can be illustrated in various types as an image in textbooks or on the board in class (e.g., a picture, a diagram, a table, etc). In this way, a teacher, educator or student can translate a problem's verbal representation into a visual mathematical representation in an effort to convey information and translate from one form of representation to another. In this way, a bridge can be created between the real world environment, the symbolic representations and the abstract world of a student's thinking, just as Goldin \& Janvier (1998) describe/interpret or define the term "representation" and "system of representation", in connection with mathematics teaching and learning (Goldin \& Janvier, 1998, p.1):

- "An external, structured physical situation, or structured set of situations in the physical environment, that can be described mathematically or seen as embodying mathematical ideas;

- A linguistic embodiment, or a system of language, where a problem is posed or mathematics is 
discussed, with emphasis on syntactic and semantic structural characteristics;

- A formal mathematical construct, or a system of constructs, that can represent situations through symbols or through a system of symbols, usually obeying certain axioms or conforming to precise definitions--including mathematical constructs that may represent aspects of other mathematical constructs;

- An internal, individual cognitive configuration, or a complex system of such configurations, inferred from behavior or introspection, describing some aspects of the processes of mathematical thinking and problem solving".

When a student understands the problem s/he can creates meaningful representations. Children have difficulty to perceive the signs of the meanings in the images of the real world. They perceive them as a whole image especially at the lower van Hiele levels. For most researchers, representations can help students to reorganize and translate their ideas using symbols. They are also useful as communication tools (Kaput, 1991) and can function as tools for understanding of concepts, since they help with the communication of ideas and provide a social environment for the development of mathematical discussion. The knowledge of supporting instruments, which are external representational systems for planning activities, allows us to choose between technological tools. The [external] representations facilitate the provision of information about the problem, capture the structure of the problem, and support visual reasoning. On the other hand, the external representations (e.g., formulations or figures) that students construct serve as an indicator of their internal representations, constituting their level of understanding and the developmental level of their geometric thinking. Chinnappan (2006) describes the process of the construction of a representation as a cyclic event:

- "The construction of representations is a cyclic event where students continue to refine one representation or change to a different one until the correct match is found between schemas that have been accessed and the goal. The goal could be unknown value that has to be determined or a mathematical result that has to be proved via a chain of reasoning. The above model suggests that instructional methods that would help students decompose problems into sub-problems would benefit them in three ways. Firstly, students might be expected to access previously acquired schemas from their memory by examining what is given in the problem. Secondly, the accessed schemas could be deployed in solution of sub-problems. Thirdly, students could relate the subproblems in ways that would help them reach the problem goal. (p.100)

How does it occur? Information-processing models have been developed to explain inter alia the problemsolving process (e.g., Newell and Simon, 1972; Bower, 1975): “[...] since external stimuli cannot get inside an organism, the representation of them [...] and their interaction is what we call "information" [...].' (Bower, 1975, p.33). Massaro \& Cowan (1993) report that "information refers to representations derived by a person from environmental stimulation [...]" (p. 384). Wertheimer (1985) also supports that "a students' representation is appropriate and satisfactory when

- the representation corresponds to the actual structure of the problem [...];

- the representation is well-integrated in the sense that all of its components are appropriately interconnected $[\ldots]$;

- the representation is well integrated with the problem solver's other knowledge [...]" (p. 22, cited in Simon, 1986, p.249).

Moreover, cognitive researchers are investigating how these activities are processed from a psychological point of view and concretely in terms of how the students perceive the information on the computer screen, what parts of their brain are stimulated as they explore using different interaction techniques, and how they integrate and embody this information to their pre-existing knowledge. The questions posed here relate to the external stimulation delivered by new representational infrastructures. When a student reads a mathematical problem, information relating to the problem transits through the sensory register into their working memory. Sensory register is the unit where a stimulus is registered (Atkinson \& Shiffrin, 1968). Working memory is the unit of the brain-memory "where the information is temporarily stored and processed" (Karadag, 2009, p.31). The use of a computing environment as dynamic geometry (DGS) facilitates the teaching and learning of Euclidean geometry and helps students overcome the difficulties in translation between representations through automatic translation or "dyna-linking"(Ainsworth, 1999, p. 133). Moreover, mental representations are stimulated in response to the problem and retrieved from their long-term memory, along with components of interrelated information from student's pre-existing knowledge. The next step is the incorporation of new information into the pre-existing structural units in the student's mind. In the words of Lester \& Kehle (2003):

"Successful problem solving in mathematics involves coordinating previous experiences, knowledge, familiar representations and patterns of inference, and intuition in an effort to generate new representations and related patterns of inference that resolve the tension or ambiguity (i.e. lack of meaningful representations and supporting inferential moves) that prompted the original problem-solving activity. (p. 510) 
The problem-solving process, including diagram construction, can be experienced using a "brainstorming technique" session, which is regarded as the most effective tools we know about creative problem-solving (e.g., Osborn, 1953). In a "brainstorming technique" session, students express/formulate what they know with the teacher helping them by introducing the concepts through essential questions, writing their ideas on the board and organizing them into a "concept map" (e.g., Novak, 1990), using also an approach inspired by history or a historical contextualization of the meanings included in the problem. Brainstorming technique depends on the students' thinking to create connections among meanings (e.g. when a student hears the meaning of the Pythagorean theorem, his/her brain automatically associates it with the meaning of square as well as with a formula connecting the sides of the right triangle). Researchers (e.g., Iraksen, 1998) have found that brainstorming is an effective technique for students to develop their cognitive skills by generating and organizing their ideas. The whole process can enhance cooperative learning as well as encourage student engagement in the learning process by dealing effectively with students' cognitive conflicts and improving their critical thinking skills. Many students are not able to translate the verbal representation of a geometrical problem into an iconic representation during the problem-solving process. And even if the students overcome this obstacle with the help of the teacher, many do not know how to continue the process, especially in the case of geometrical problems.

Cognitive conflicts and cognitive obstacles, "aha" phenomena and enthusiasm occur many times over during the problem-solving process as a student works individually or in cooperation/interaction with other students and the teacher. In other words, the problem-solving process combines characteristics from the theoretical background of constructivist learning, of discovery learning, and of learning through social interaction. Mathematical problem solving process concepts can also be introduced informally and subsequently connected formally to the theory.

\section{Modeling a real-world problem in a DGS environment}

If the students are engaged in solving a real world problem this process is underlied by the characteristics of the philosophy of Realistic Mathematics Education (abbreviated as RME), developed at the Freudenthal Institute and restricted here to the aspect that mathematics should be learned as an activity of progressive mathematization, distinguished to horizontal mathematization and vertical mathematization (e.g., Treffers,1987; Gravemeijer, 1994; Van den Heuvel-Panhuizen, 1996; Drijvers, 1999).

Horizontal mathematization in real world situations refers to the process of modeling from the real world to the model world using mathematical representations. In other words, horizontal mathematization is a process through which a real problem is transformed to a model. Vertical mathematization concerns the mathematical abstract process in a higher level of abstraction, connecting concepts and strategies.

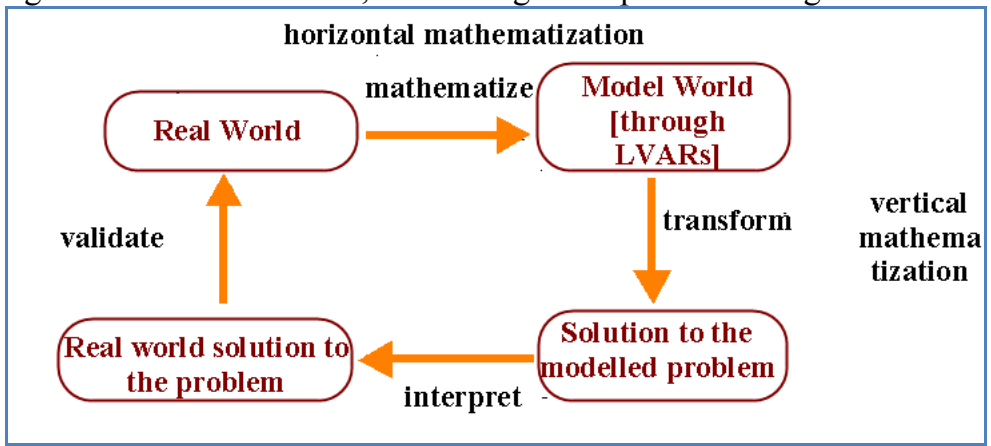

Fig. 4. Modeling as a cyclic process (Doerr \& Pratt , 2008, p. 262): an adaptation for the current study

Doerr \& Pratt (2008) in their article "The Learning of Mathematics and Mathematical Modeling" state that:

"A model is a system of objects, relationships, and rules whose behavior resembles that of some other system. Modeling is the activity of mapping from one system to another. This activity is driven by the need to describe, predict, or explain some particular phenomena of interest to the modeler. Elements from the real world of the experienced phenomena are selected, organized, and structured in such a way that they can be mapped onto a model world. This model world necessarily simplifies and distorts some aspects of the real world while maintaining other features and allowing for manipulations of these features (or objects) in accordance with the rules of the model world". (p.261)

Corte, Verschaffel \& Greer (2000) support also that "the [...]process of modeling constitutes the bridge between mathematics as a set of tools for describing aspects of the real world, on the one hand, and mathematics as the analysis of abstract structures, on the other" (p.71). If the teaching and learning is based on real -world problem solving modeled in a DGS environment the teacher

"[...] apart from the aspect of anticipating the mental activities of the students, [...] has to investigate whether the thinking of the students actually evolves as conjectured, and he or she has to revise or adjust the learning trajectory on the basis of his or her findings. In relation to this, Simon (1995) speaks of a 
mathematical teaching cycle. In a similar manner, Freudenthal (1973) speaks of thought experiments that are followed by instructional experiments in a cyclic process of trial and adjustment." (Gravemejer, 2004, p.9).

In previous studies I have supported the effect that the Linking Visual Active Representation modes (Patsiomitou, 2008 a, b, 2010, 2012 a, b) have on the student's gradual competence towards rigorous proof construction, during a problem solving process. "Linking Visual Active Representations" (LVARs) during a dynamic geometry problem solving session are defined as follows (e.g, Patsiomitou, 2008a, b, 2010, 2012a, b), incorporating the meaning of instrumental decoding (Patsiomitou, 2011, $12 \mathrm{a}, \mathrm{b}$ ):

Linking Visual Active Representations are the successive/consequential building steps in the dynamic representation of a problem or between problems, which repeat the same procedural steps or steps reversing a procedure in the same phase or between different phases of a hypothetical learning trajectory. LVARs reveal an increasing structural complexity by conceptually and structurally linking the transformational steps taken by the user (conducting anticipatory thought experiments) through the interaction techniques provided by the software as a result of his/her development of thinking and understanding of geometrical concepts, which are instrumentally decoded by the way s/he has visualized mentally what exist in his/her mind or a revision of it.

Reflective Visual Reaction is the reaction based on a reflective mode of thought, derived from interaction with LVARs in the software.

A DGS environment like Sketchpad or Web Sketchpad is a perfect means to support the LVAR process. I very often try to make a mental shift from an observer's point of view to an actor's point of view (Cobb, Yackel \& Wood, 1992 in Gravemeijer, 2004) when designing activities, interchanging the predetermined student and teacher roles in my mind. By this, I mean that I place myself (as an observer) in the position of my students (as actors), trying to think as a student and responding to my own questions: How can a student perceive a mathematical meaning through a concrete learning path? Are the procedures sequential and the diagrams complementary? Do the activities help my students to recall preexisting structures? Clements \& Sarama (2014) point out:

"[...] When [the teachers] interact with the student, teachers also consider their own actions from the student's point of view. [...]. Thus, the benefit for the teacher is to have a well-formed and specific set of expectations about students' ways of learning-a likely path that incorporates the big, worthwhile ideas" (p. 23).

To produce a mathematical model from a word problem in Sketchpad, you can combine a picture of reality with a diagram with concrete conceptual properties, to drawing the students' attention through interaction techniques to important properties which are essential for an investigation of the problem. This serves to reveal the theoretical object. Burger \& Shaughnessy (1986) support that instruction in a successive sequence of increasing complexity has positive effects on students' development of thinking. The different LVAR modes can be built using a combination of different transformational processes and interaction techniques supported by the Sketchpad environment. The LVAR modes are described as follows (e.g., Patsiomitou, 2008b, pp. 169-174):

Mode A-the inquiry/information mode: In this phase of the problem, the students familiarize themselves with the field under investigation using the instantiated parts of the diagrams which lead them to discover a certain structure.

Mode B-the directed orientation mode: In concrete terms, the sequential linked constructional steps of the solution to the problem emerge step-by-step.

Mode C-the explicitation mode: Transformations in increasingly complex linked dynamic representations of the same phase of the problem modify the on-screen configurations simultaneously.

Mode D-the free orientation mode: Every phase in the solution can be displayed side by side on the same page of the software in an overview.

Mode E-the integration mode: Successive configurations on different pages that are linked cognitively and not necessarily constructionally, compose the solution to the problem in global terms as a series of steps.

To create a dynamic diagram during the Linking Visual Active Representations (LVARs) design process in the Geometer's Sketchpad environment, I used a diverse set of interaction techniques including "animating" a point on its path, "tracing" a segment, "hiding and showing" action buttons, and "linking" or "presenting" action buttons, or a combination of interaction techniques (Patsiomitou, 2008a, b; 2010; 2012a, b), to achieve students' interaction. I linked sequential actions over multiple pages of the software or linked the steps in the representation of the problem in order to lead students to a cognitive linking of the used representations, based on the work of Kaput which supports that linking representations "creates a whole that is more than the sum of its parts [...] (Kaput, 1989) and creates a "temporal sequence of the constructions' steps representing the counterpart of the logic hierarchy between the geometric properties of a figure" (Mariotti, 2002, p. 686). The design and redesign of activities for the teaching and learning processes, with real problems through LVAR in 
the dynamic geometry software, and the results obtained from the research data (e.g., Patsiomitou, 2012 a, b), suggest that a student develops his/her abstract thinking when his/her cognitive structures are linked through conceptual representations that the student develops during the learning process.

\section{Triangles' congruence in Euclid "Elements": the visual impact in a DGS}

Many researchers, mathematicians and mathematics educators (e.g., Bell, 1976; Hanna, 1983; de Villiers, 1990 , 1999; Hanna \& Jahnke, 1996; Marrades \& Gutierrez, 2000; Varghese, 2017) have recognized different functions of proof and proving as: verification, justification, explanation, discovery, systemization etc. because the proving process can provide insight and discovery, justify or verify why a statement is true. Complementary to this, a deductive system of axioms, theorems and propositions as well as concepts and definitions can help the student to organize the proving process.

"There is no other scientific or analytical discipline that uses proof as readily and routinely as does mathematics. This is the device that makes theoretical mathematics special: the tightly knit chain of reasoning, following strict logical rules, that leads inexorably to a particular conclusion. It is proof that is our device for establishing the absolute and irrevocable truth of statements in our subject. This is the reason that we can depend on mathematics that was done by Euclid 2300 years ago as readily as we believe in the mathematics that is done today. No other discipline can make such an assertion" (Krantz, 2007, p.1)

The postulates determined by Euclid in his "Elements" regulate geometrical deductive reasoning, formulating the "rules" by which a person can synthesize a proposition in a meaningful and logical manner. According to historians and scholars Euclid's "Elements", was considered to be the most influential textbook. It has been posited that the "Elements" is the second most printed book after the Bible. In the words of Dionysius Lardner (1855) in the preface of his book "The first six books of the Elements of Euclid":

"Two thousand years have now rolled away since Euclid's Elements were first used in the school of Alexandria, and to this day they continue to be esteemed the best introduction to mathematical science. They have been adopted as the basis of geometrical instruction [...and] has been adopted as a universal standard".

Evaggelos Stamatis (1957) concretely reports:

"The first Book of "Elements" includes 23 definitions, 5 postulates, 9 Common Notions and 48 Propositions and problems [...]. The first 26 Propositions concern triangles in general [...]. The proving methods in "Elements" are four: synthetic, analytic, proof by contradiction, and proof by induction [...]. Using the synthesis method, when we try to prove a geometric proposition, we proceed from well-known proposals based on definitions and axioms and arrive at the truth of the proposed proposal through a series of appropriate reasoning." (p.17) (my translation of Evaggelos Stamatis' Greek-language manuscript).

The synthetic method synthesizes basic objects of Euclidean Geometry (e.g. points, lines) in a formal way using definitions, axioms and propositions. Speaking of logical inferences and deductive argumentation, for me the propositions regarding triangle congruence in Euclid "Elements" are crucial for students to understand and implement in the problem-solving process. Can these fundamental propositions of plane geometry in which triangles are congruent, (included in Book 1 of Euclid's Elements) be transformed in a DGS software? I shall explain their instrumental decoding in Sketchpad in the light of having in mind the following excerpt written by Dina van Hiele (Fuys et al, 1984)

"[...] the deductive system of Euclid from which a few things have been omitted cannot produce an elementary geometry. In order to be elementary, one will have to start from the world as perceived and as already partially globally known by the children. The objective should be to analyze these phenomena and to establish a logical relationship. Only through an approach modified in that way can geometry evolve that may be called elementary according to psychological principles" (p.24)

This is in accordance with what Furinghetti \& Paola (2003) support:

[...] When [Greek geometers] made proofs they were not inside a theory in which axioms were explicitly declared. Initially antique geometry developed in an empirical way, through a naïve phase of trials and errors: it started from a body of conjectures, after there were mental experiments of control and proving experiments (mainly analysis) without any sure axiomatic system. According to Szabo, this is the original concept of proof held by Greeks, called deiknimi. The deiknimi may be developed in two ways, which correspond to analysis and synthesis" (p.398)

"Deiknymi" or "apodeiknio" in Greek (translated as "proving" in English) can be represented visually in a dynamic geometry system (DGS) using LVARs (e.g., Patsiomitou, 2008c, 2009). In other words, "deiknimi" can be visualized using Sketchpad' interaction techniques (for example, custom tools, "animating" tools, "tracing" tools, "hiding and showing" action buttons, and "linking" or "presenting" action buttons, or a combination of interaction techniques in Sketchpad) (e.g., Patsiomitou, 2008a, b; 2010; 2012a, b). The interaction with LVARs 
has two aspects similar to what Sedig, Rowhani, \& Liang (2005, p.422) support regarding VMRs: "the action upon a representation by the user through the intermediary of a human-computer interface, and the representation communicating back through some form of reaction or response." Lopez-Real and Leung (2006) state that DGS including dragging "[...] as a fundamental geometrical object (like that of point, circle)," determines "new 'rules of the game,' or even a new game for geometry" (p. 676).

The three cases in which triangles are congruent are illustrated in the figures 5, 6 and 7.

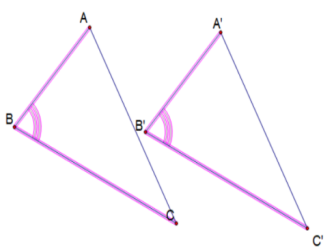

Fig. 5. A diagram for Euclid's Proposition I.4 in Sketchpad.

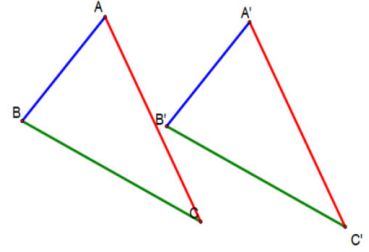

Fig. 6. A diagram for Euclid's Proposition I.8 in Sketchpad.

$\delta^{\prime}$.

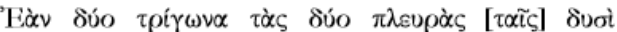

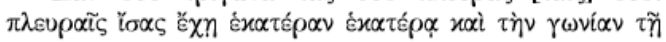

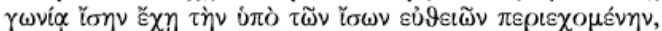

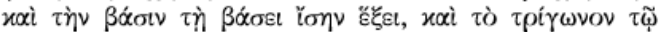

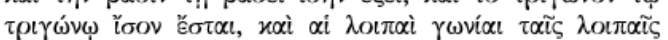

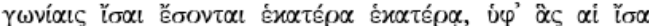

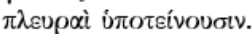

Fig. 8. Screenshot of an excerpt included in Fitzpatrick (2007, p.10)

Proposition I.4 (known with the abbreviation SAS): If two triangles have two corresponding sides congruent and the angles enclosed by the equal sides congruent the two triangles are congruent (SAS)

We can take it as given that two segments are congruent if they have the same "length" and, similarly, that two angles are congruent if they have the same "angle measure". The method used by Euclid to prove proposition I.4, regarding triangle congruence is a combination of: the method of superposition and the method of proof by contradiction. Initially, the first part of the proposition is proved by moving one of the two triangles so that one of its sides coincides with the other triangle's equal side; it is then proved that the other sides coincide as well. (See Website [2])

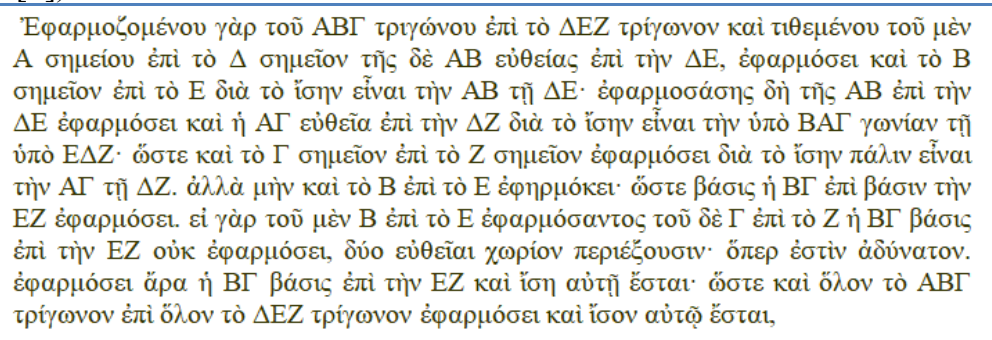

Fig. 9. Screenshot of an excerpt of the proof used by Euclid to prove proposition I.4, mentioned in Euclid "Elements" (See Website [3])

The paragraph mentioned above in Ancient Greek is translated as follows (Fitzpatrick, 2007, p.10):

" $[\ldots]$ Let the triangle $\mathrm{ABC}$ be applied to the triangle $\mathrm{A}^{\prime} \mathrm{B}^{\prime} \mathrm{C}$ ', the point $\mathrm{A}$ being placed on the point $\mathrm{A}^{\prime}$, and the straight-line $\mathrm{AB}$ on $\mathrm{A}^{\prime} \mathrm{B}^{\prime}$. The point $\mathrm{B}$ will also coincide with $\mathrm{B}^{\prime}$, on account of $\mathrm{AB}$ being equal to $\mathrm{A}^{\prime} \mathrm{B}^{\prime}[\ldots]$. For, if $\mathrm{B}$ coincides with $\mathrm{B}^{\prime}$, and $\mathrm{C}$ with $\mathrm{C}^{\prime}$ and the base $\mathrm{BC}$ does not coincide with $\mathrm{B}^{\prime} \mathrm{C}^{\prime}$, then two straight lines will encompass an area. The very thing is impossible. Thus, the base $\mathrm{BC}$ will coincide with B' $\mathrm{C}^{\prime}[\ldots]$ '..

According to Krantz (2007)

"One of the most important proof techniques in mathematics is "proof by contradiction". With this methodology, one assumes in advance that the desired result is false and shows that that leads to an untenable position. But in fact proof by contradiction is nothing other than a reformulation of modus ponendo ponens" (p.6)

Moreover, in the words of Lardner (1855)

"Superposition is the process by which one magnitude may be conceived to be placed upon another, so as exactly to cover it, or so that every part of each shall exactly coincide with every part of the other" (p.5). [...] In the superposition of the triangles in this proposition, three things are to be attended to: (a) The vertices of the equal angles are to be placed one on the other. (b) Two equal sides to be placed one on the 
other. (c) The other two equal sides are to be placed on the same side of those which are laid one upon the other. From this arrangement the coincidence of the triangles is inferred (p. 18).

In the Sketchpad software, this method could be instrumentally decoded (Patsiomitou, 2011) by a user using translation transformation, a digital method of "superposition", in which a figure is transferred to another point in space, using a dynamic vector. Concretely, the triangle on the right $\left(\mathrm{A}^{\prime} \mathrm{B}^{\prime} \mathrm{C}^{\prime}\right)$ can be produced using the translation transformation, on the triangle $\mathrm{ABC}$. A combination of transformations (translation \& dragging) also indicates the triangles' congruency by a superposition method. The students can also apply the triangle ABC on the triangle $\mathrm{A}^{\prime} \mathrm{B}^{\prime} \mathrm{C}^{\prime}$ and justify why this is the case. We can also use predesigned movement action buttons to move the triangle $\mathrm{ABC}$ onto the triangle $\mathrm{A}^{\prime} \mathrm{B}^{\prime} \mathrm{C}^{\prime}$ so the two can be superposed confirming the triangles' congruency. We can use Sketchpad's customized 'appearance tools' to indicate the congruent angles, and we can also highlight or color the triangles' corresponding congruent sides in order to point out the congruency. These are the signs that can be visualized by a student during the investigation of the concrete theorem and which indicate congruency. The students can also measure the angles and the sides, and investigate the congruency of the triangles through experimental dragging (e.g., Patsiomitou, 2011; 2012a, b) the congruency of the triangles and the power of the theorem. In other words, the experimental dragging leads to a theoretical observation.

\section{From Pythagoras' theorem to Vecten's theorem}

6.1. Pythagoras theorem (in Euclid's elements): a DGNA problem using an LVAR version (3rd mode)

I have created the three consequential visual representations using the translation transformation (Fig. 10). Every object of the first construction on the left has been translated by the vector $\mathrm{j}$ to an image object on the right and the outline figure can be superposed on it. Every representation on the right is more complex and supports the next consequential step on the problem's solution. Nunokawa \& Fukuzawa (2002), report Sohma (1997) who stated that "he wanted his students to experience a feeling of 'why?' so that they would be motivated to solve [geometry] problems" (p.31). As they support "the students' feeling of 'why?' was influenced by their understanding of a problem situation" (p. 41). In the current situation the students ask themselves "why is this happening?" at every sequential step. For example, they might ask: why does triangle EFL has an area congruent to the area of the triangle E'L'M'? (: they have the same base EL and the heights of the triangles to the base EL are equal magnitudes). Thiele (2003) explains the meaning of magnitude as follows:

"There is no definition of the concept of magnitude (Greek megathos) because there is no superior concept for this fundamental concept. Nevertheless, Euclid is dealing with magnitudes throughout the Elements; [...] Magnitudes are generally characterized by the property of being able to increase and decrease." (Thiele, 2003, p. 6)

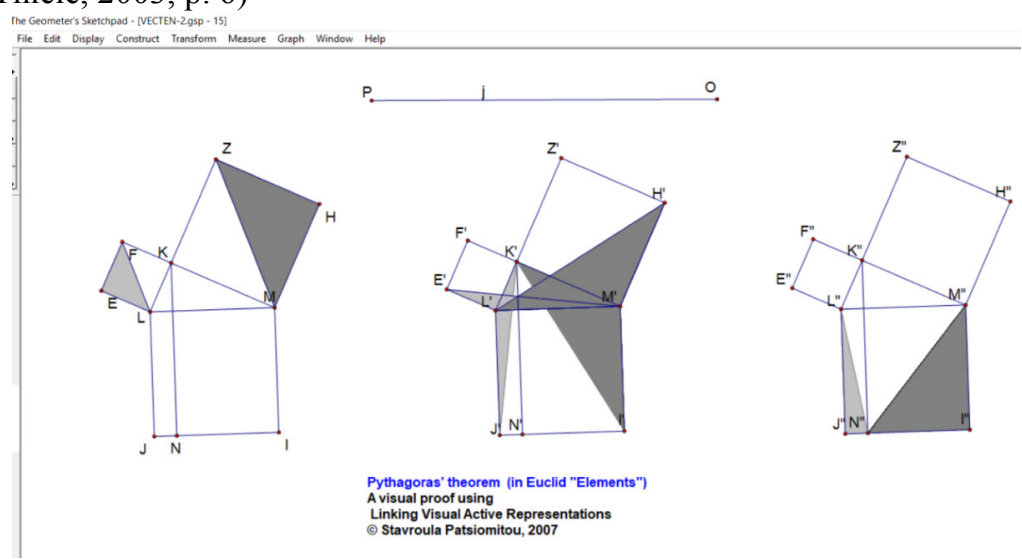

Fig. 10. Proposition I.47 using LVARs (Mode 3): A visual proof in three linking diagrams.

The following questions could also support the structure of the Euclidean proof:

- Why does triangle E' $\mathrm{L}^{\prime} \mathrm{M}^{\prime}$ has an area congruent to the area of the triangle $\mathrm{K}^{\prime} \mathrm{L}$ 'J? (: they are congruent triangles, so they have congruent areas).

- Why triangle $\mathrm{K}^{\prime} \mathrm{L}$ 'J has an area congruent to the area of the triangle $\mathrm{L}^{\prime \prime} \mathrm{J}^{\prime \prime} \mathrm{N}^{\prime \prime}($ : the base and the height of the triangles are equal magnitudes).

If we drag any point of the LVARepresentation, the image-points follow the movement also, turning the whole dynamic diagram to an active one in which we can view sequential transformations that indicate a path for the rigorous proof of the Pythagorean Theorem. The triangle EFL is visually transformed to the triangle E' $\mathrm{L}^{\prime} \mathrm{M}$ ', then to the triangle $\mathrm{K}^{\prime} \mathrm{L}$ 'J, and finally to the triangle $\mathrm{L}^{\prime \prime} \mathrm{J}^{\prime \prime} \mathrm{N}^{\prime \prime}$. Similarly, the triangle ZHM is visually transformed to the triangle $\mathrm{L}^{\prime} \mathrm{M}^{\prime} \mathrm{H}^{\prime}$, then to the triangle $\mathrm{K}^{\prime} \mathrm{M}$ 'I and finally to the triangle $\mathrm{M}^{\prime \prime} \mathrm{N}^{\prime \prime} \mathrm{I}^{\prime \prime}$ (Fig. 11). Consequently, the area of the square FKLE plus the area of the square ZHMK is transformed into the area of the square LMIJ. We can also create an LVARepresentation using more sequential steps, every object on the right 
side occurs as a translation image of the object on the left side (Fig. 11). The whole process scaffolds students thinking, given that they cannot visualize / hold all the intermediate steps in their heads for the solution.

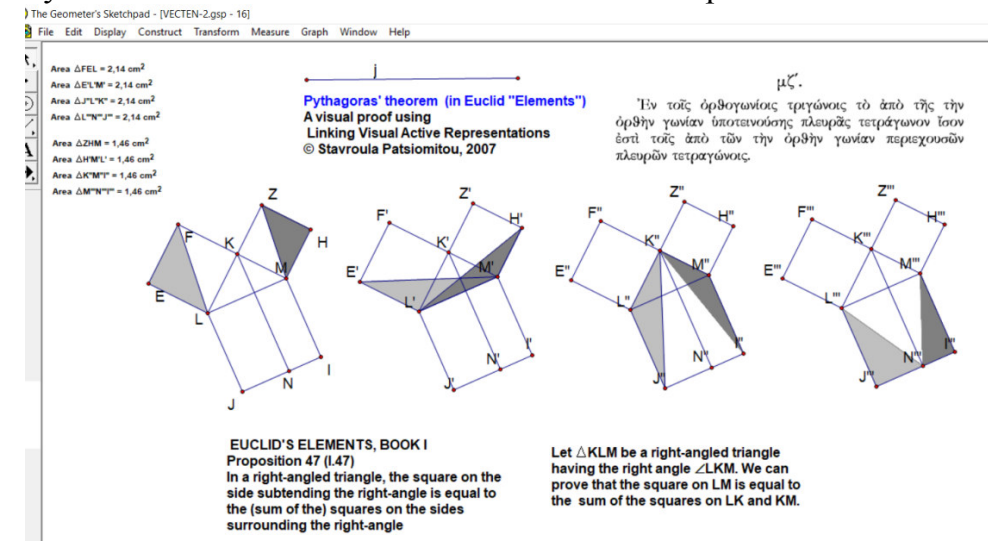

Fig. 11. Proposition I.47 using LVARs (Mode 3): A visual proof in four linking diagrams

If the vector's length is tending to zero, then the vectors' endpoints coincide. This result to the following representation illustrated in Fig. 12 in which we can view the initial triangle EFL transformed to the final triangle LJN, as well as the auxiliary triangles for the visual proof in blue and yellow (i.e., the sequential diagrams have been superposed to the first diagram on the left).

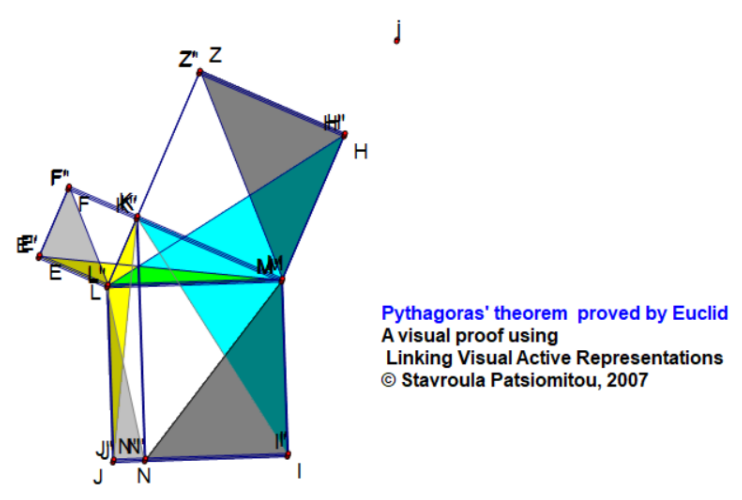

Fig. 12. Proposition I.47 using LVARs (Mode 3):

\subsection{Vecten's theorem: a DGGA problem}

I have considered Vecten's theorem to be particularly interesting since 1985, when I investigated all the subproblems reported in "Jesuit Geometry" (translated in Greek) with great interest. In the current work I shall describe a few sub-problems of the Vecten's theorem and their solution. I introduced a pseudo-Toulmin's model (Patsiomitou, 2011, 2012a, b, 2018b) --based on Toulmin's model (1958) -- in which: (1) the data could be the dynamic diagram, or an object and (2) a warrant could be a tool or a command that guarantees the result which is the claim (or the resulted formulation). Also, I have extended the pseudo-Toulmin's model in order to express a relationship between the figures. The solutions of sub-problems in Vecten's theorem are presented here, pointing out the propositions regarding triangles' congruence.

Vecten's Theorem: Construct a triangle ABC. Construct two squares ABDE, ACIT, externally on the sides AB, $\mathrm{AC}$ of the triangle $\mathrm{ABC}$ respectively. Prove that

I. If $\mathrm{M}$ is the midpoint of the side $\mathrm{BC}$ then $\mathrm{AM}=\mathrm{ET} / 2$ (Fig. 13)

II. AM is perpendicular to ET. (Fig. 13)

III. If $\mathrm{O}$ is the midpoint of $\mathrm{ET}$ then $\mathrm{AO}=\mathrm{BC} / 2$.(Fig. 14)

IV. AO is perpendicular to BC. (Fig. 14)

$\mathrm{V}$. If $\mathrm{S}$ is the fourth vertex of the parallelogram EATS then the sides $\mathrm{CD}$ and $\mathrm{BI}$ are congruent and perpendicular to BS and CS respectively. (Fig. 15)

VI. If $\mathrm{G}$ is the midpoint of the segment $\mathrm{DI}$, then the $\mathrm{BGC}$ triangle is a right and isosceles triangle. (Fig. 16) 


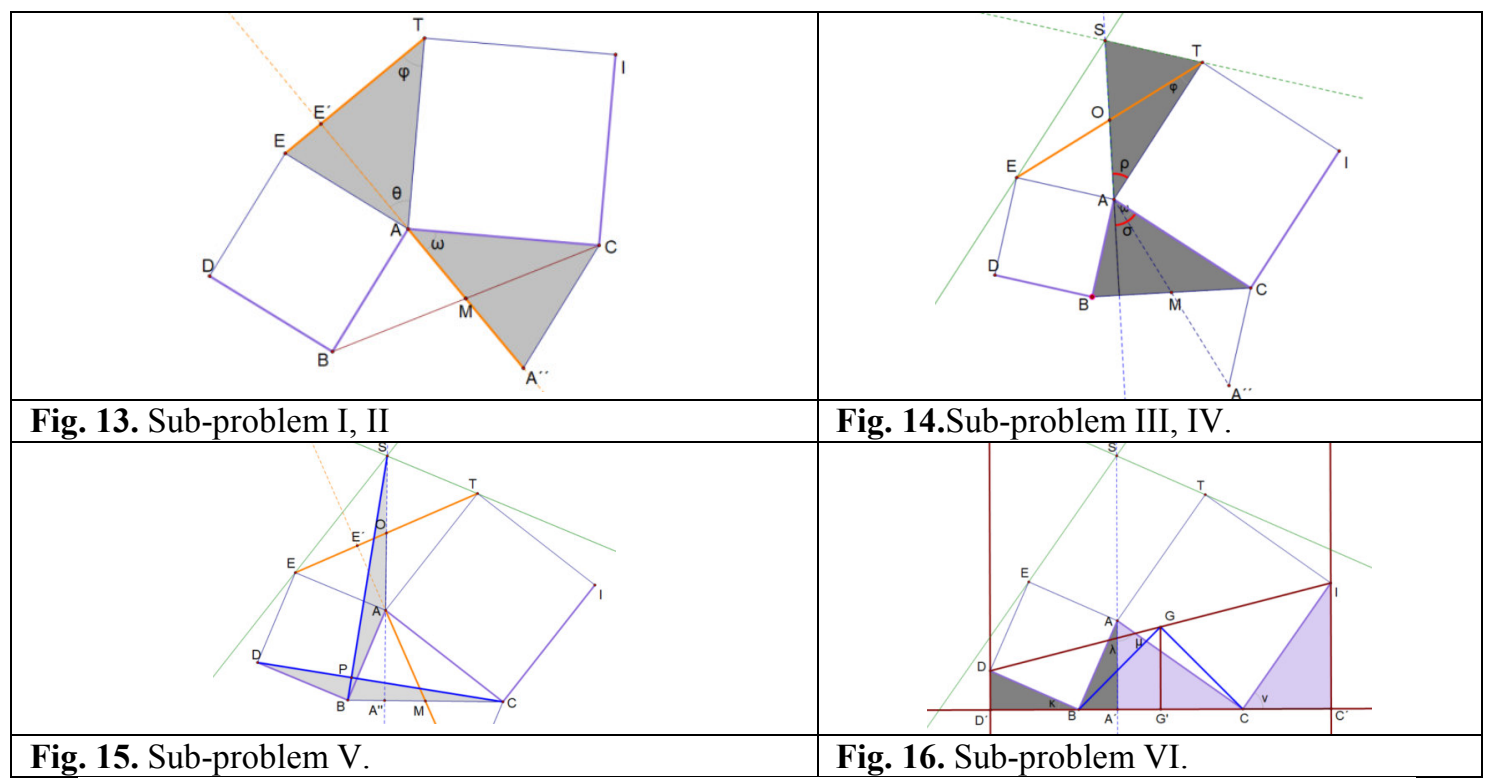

Fig. 15. Sub-problem V.

Fig. 16. Sub-problem VI.
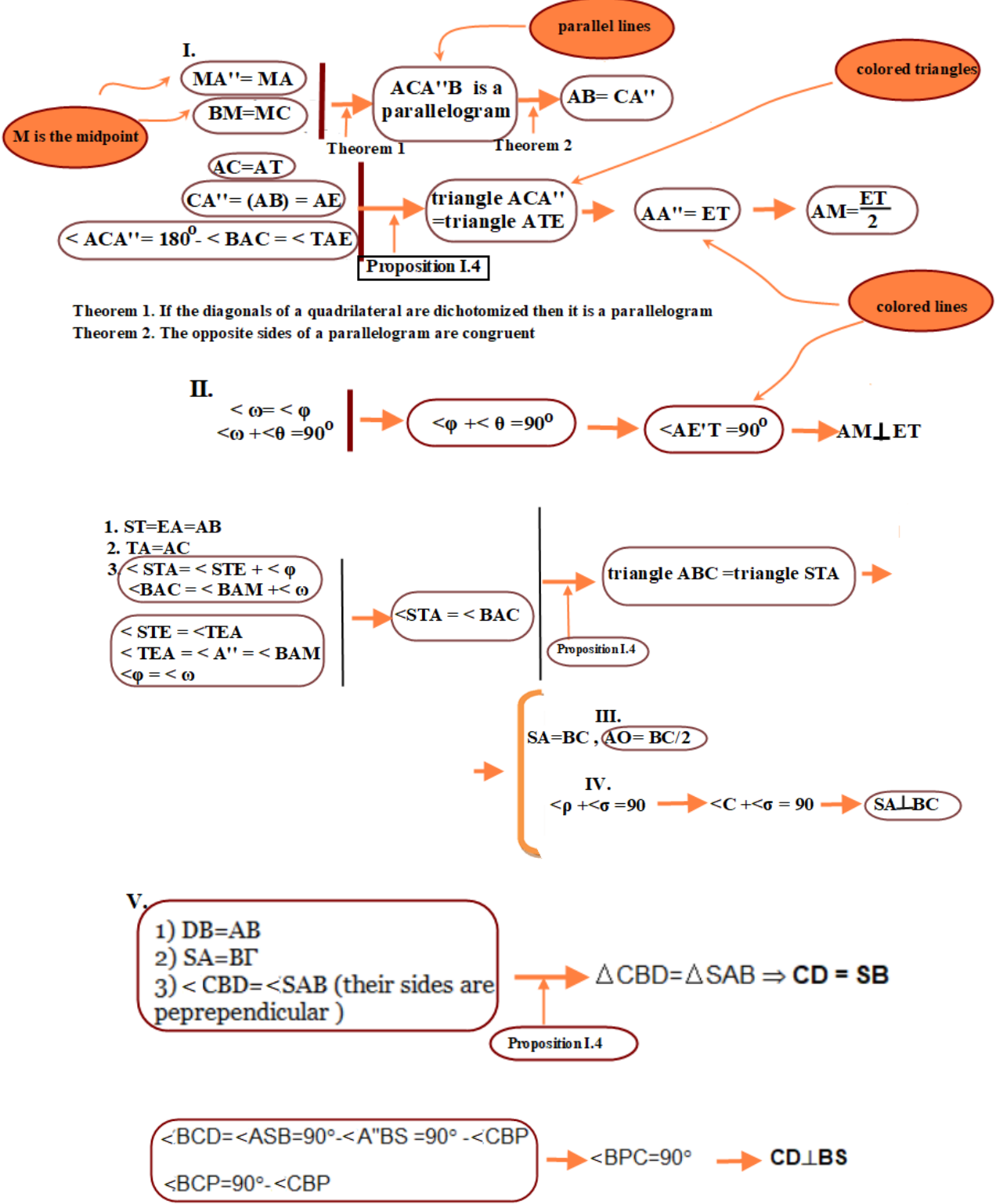
VI.
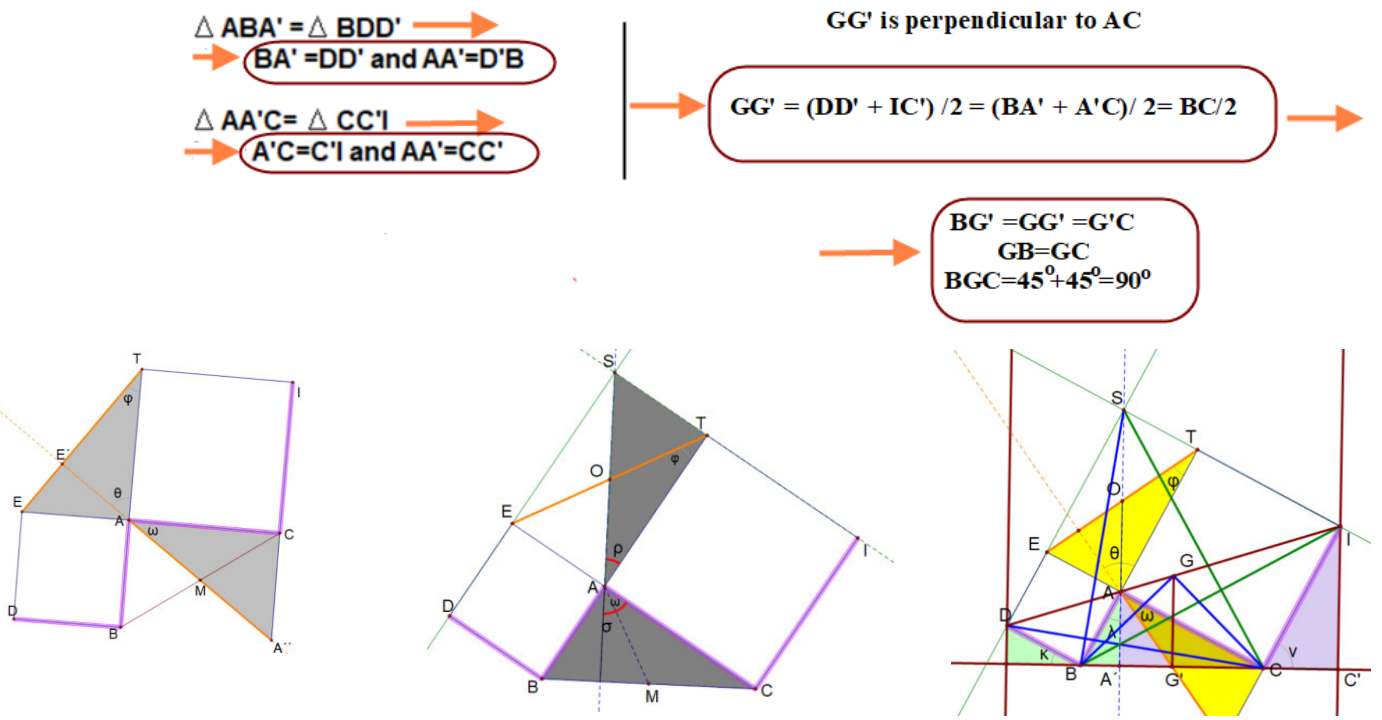

Fig. 17. Successive sequential diagrams of Vecten's sub-problems mentioned above, when the ABC is a right triangle.

If we drag the lines $\mathrm{AB}, \mathrm{AC}$ until they become perpendicular then a student has to prove that the lines $\mathrm{AE}$, $\mathrm{AC}$ belong to the same line, something that is omitted /or dismissed by the students. This part of the proof is highlighted in Euclid "Elements" (e.g., Proposition I.47) (see for example Fitzpatrick, 2007, p. 46).

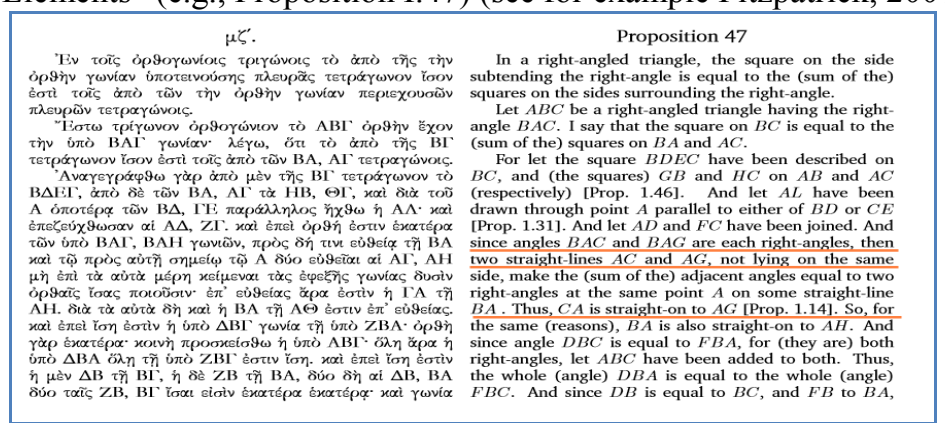

Fig. 18. Screenshot from the Proposition I.47 (Fitzpatrick, 2007, p. 46)

\section{Construction of a parametrical Vecten's hybrid diagram: a HGNA problem}

In 2005, I was experimenting with parameters and parametrical constructions in Sketchpad. For this, I decoded Vecten's theorem (Fig. 19) instrumentally using parameters (Patsiomitou, 2006, in Greek, pp. 1270-1273) (i.e., the sides $A B=a, A C=b$ as well as the angle $\angle B A C=f$ has been constructed by using parameters) in order to investigate more deeply the properties of Vecten's theorem. Firstly, speaking of a DGS environment, it is important to identify the meanings of geometrical objects in such an environment.

- I will use the meaning of dynamic geometrical object, to denote every object that has been constructed in a dynamic geometry software interface. This object could be a "drawing" or a "figure" which intrinsically has dynamic properties. Gonzalez and Herbst (2009) have defined the dynamic diagram as "a diagram made with DGS and that has the potential to be changed in some way by dragging one or more of its parts" (p.154).

- I will use the meaning of dynamic diagram, to denote an external representation composed out of a set of rationally related dynamic objects in a DGS environment. A dynamic diagram can be a simulation of a problem modeled in the DGS environment, which includes many geometric objects and combinations of interaction techniques implemented in these objects. 


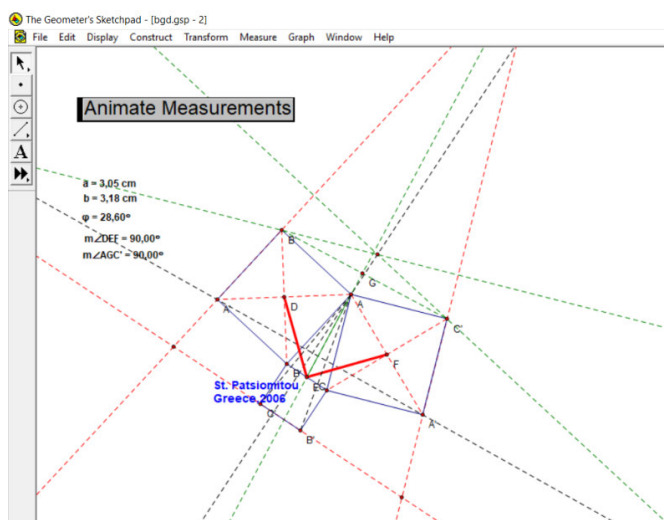

Fig. 19: Screenshot of Vecten' theorem in Sketchpad using dynamic parameters (Patsiomitou, 2006, pp. 12701273 , in Greek)

- I will also introduce the meaning of dynamic section to denote a set of dynamic diagrams that are linked to each other procedurally and conceptually, even if they differ structurally. A dynamic section contains meanings belonging to the same class that are united or joined into a whole, which in the concrete situation symbolically means they exist in one [alive book] section or they are dynamically linked. As I have written in a previous work (Patsiomitou, 2018b, p.40):

"A first and very important effect on students' thinking stems from the Sketchpad software allowing the user to create sequential linking pages so that the whole Sketchpad file becomes an "alive book" (Patsiomitou, 2005, $p$. 63, in Greek; Patsiomitou, 2014). The "alive digital representations" (Patsiomitou, 2005, p. 67) function, which makes the whole figural diagram "alive", giving the students the potential to focus their attention on simultaneous modifications (and transformations) of objects on the screen (Patsiomitou, 2005, p. 68), also yielded important results during my investigations". In the Geometer's Sketchpad environment (or the Web Sketchpad) anyone can create a dynamic section by linking pages in the same file. In this way, a solution to a problem can be separated into sequential componential steps that help a student to create linking mental representations in his/her mind (Patsiomitou, 2012, 2013, 2014, 2018a, b).

- I will introduce the meaning of hybrid object to denote an on-screen geometric object that is intrinsically dynamic but remains untransformed /unaltered on screen, even though dynamic dragging is applied or implemented on it. This situation comes about because of the hybrid object's dependence from its parent objects.

Many researchers use the word "hybrid" to denote something that does not obviously belong in a given class of objects, or a mixed entity composed of different elements. Verillon \& Andreucci (2006) for example in their study "Artefacts and cognitive development: how do psychogenetic theories of intelligence help in understanding the influence of technical environments on the development of thought?" report Rabardel (1995) who argued that during instrumental genesis "the resulted instruments are actually hybrid entities, on the one part are psychological and on the other part artefactual" (p.12). Morgan et al. also mention the representational hybrid nature of the Turtleworlds environment, because it behaves like a hybrid between Logo and Dynamic Manipulation systems due to the 'variation tool' (Morgan et al. https://www.itd.cnr.it/telma/docs/Rep_Del_Draft3.pdf, p.7). Cerulli (2004) also mention "a hybrid language to be used to bridge the natural language with the mathematical one" (p.36) [...] As Cerulli states "the evolution of meanings is based on the idea of deriving, from a used instrument, hybrid signs which refer both to the practice with the instrument and to the sphere of theory of mathematical knowledge" (p. 142). We could also introduce the meaning of hybrid diagram in the DGS environment to denote the untransformed on-screen diagram, which has been created to stay hybrid and become dynamic if we implement a transformation on its parents. The diagram is intrinsically dynamic, but a user could use it as an image or a static diagram, if $\mathrm{s} / \mathrm{he}$ does not know how to make it dynamic. It is important to point out at this point that: the transformation of objects in a DGS environment is dependent on whether these objects have been defined, as hybrid objects or not. In the current case (Fig. 19, 20, 21, 22) the whole representation is a hybrid diagram, meaning it is completely determined by its parameters and cannot be moved if we drag any point on it. The diagram has intrinsically dynamic properties, but is different from a dynamic diagram created using the 'Construct' or 'Transform' menu in that. It can only be altered if we animate its parameters, supporting a visualization of infinite occasions of dynamic objects which maintain the same structure but they are modified in a mereologic, optic and place way in the words of Duval (1999). 

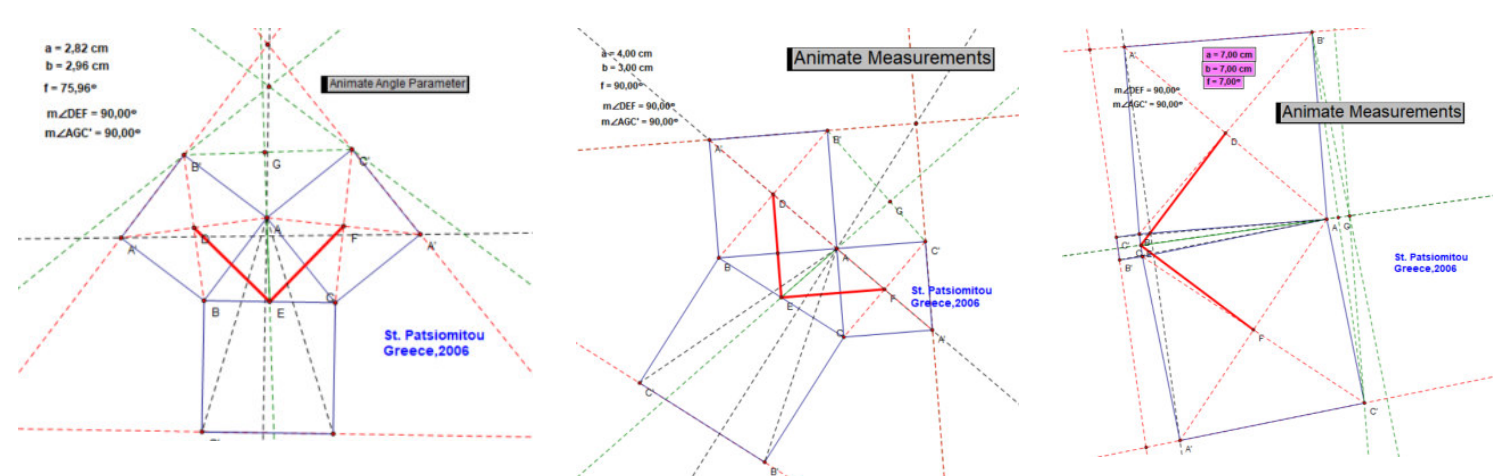

Fig. 20, 21, 22: Screenshots of the sequential diagrams of Vecten's theorem in Sketchpad produced by animation of angle's parameter.

If we animate only the parameter of angle $\mathrm{f}$ (the angle between segments $\mathrm{AB}, \mathrm{AC}$ ) we can transform the parametrical hybrid object as it is viewed in the screenshots (Fig. 20,21,22). The animation of all parameters is a direct object manipulation which transforms every part of the object. This leads to a kind of algebraic geometry, which takes the parametric sides and angles as input and provides a continuous transformation of the diagram as output (Patsiomitou, 2006, pp.1270-1273, in Greek). According to Leron \& Paz (2006) in their work "The slippery road from actions on objects to functions and variables"

"to be specific, the metaphorical mapping would map action to function, object (or the state of the object) to variable, and the initial and final state of the transformed object to the function's input and output." (p. 128)

A student's action on parameters leads to a transformation of objects perceived as basically external. The students can also investigate a concrete situation of the hybrid-dynamic representations, choosing to assign concrete magnitudes to the parameters (Fig.22). Moreover, the user can directly perceive infinite alterations of the same figure on screen (Patsiomitou, 2006, p. 1273, in Greek) and conceive of an abstract mathematical object. This mode of construction is completely different from the simple construction mode which uses dynamic tools, because the student consciously perceives the modification of the dynamic objects on screen. We can thus speak about functional geometry and through the conservation of figures' properties about the concept of geometrical function.

\section{From Vecten's theorem to Gamow's problem: a RGNA problem}

In year 2007, I turned my investigations of Vecten's theorem to its known version as a real- world problem, created by Gamow (1948, reprinted 1988) through modeling it in Sketchpad DGS environment (e.g., Patsiomitou, 2008a, b) inspired by a work of Daniel Scherr (2003), regarding the concrete problem. Daniel Scher (2003) designed the activity in multiple linked pages using Sketchpad v4. Previously, I also discussed the concrete problem with Professor Paris Pamfilos and Professor Constantinos Christou, when I was experimenting, using the Euclidraw Dynamic Geometry program (Website [4]). Gamow's (1948, reprinted 1988) problem involving pirates and buried treasure seemed ideal for my students. I enhanced the problem with historical evidence from Homer, seeking thus to motivate my students to develop their interest in ancient history through geometry. Gamow's problem hinges on a treasure map found in an old man's attic. Here is the revision (Patsiomitou, 2008a, p. 357):

"In the Odyssey, Homer (c74-77) mentions that the pirates also raided Greek islands. The pirate in our story has buried his treasure on the Greek island of Thasos and noted its location on an old parchment. "You walk directly from the flag (point F) to the palm tree (point P), counting your paces as you walk. Then turn a quarter of a circle to the right and go to the same number of paces. When you reach the end, put a stick in the ground (point K). Return to the flag and walk directly to the oak tree (point O), again counting your paces and turning a quarter of a circle to the left and going the same number of paces. Put another stick in the ground (point $\mathrm{L}$ ). The treasure is buried in the middle of the distance of the two sticks (point T)."'(Figure 23, 24, 25) After some years the flag was destroyed and the treasure could not be found through the location of the flag. Can you find the treasure now or is it impossible?"

Many researchers have been attracted to the problem (e.g., De Villiers, 1999). I considered the problem as particularly interesting because it allows three quite different approaches (Patsiomitou, 2008a, p. 366): (i) the socalled 'static' approach; (ii) a software-supported: 'dynamic' approach; and (iii) a paper and pencil 'dynamic' approach concerning dynamic methods in geometry, consisting of 'thinking in motion' in a paper pencil environment. In the current paper I shall describe how I designed mode A and mode C, trying to concentrate on two of its aspects: 1) linking actions with constructional steps in the software, and 2) linking the various visual steps in the proving process. 

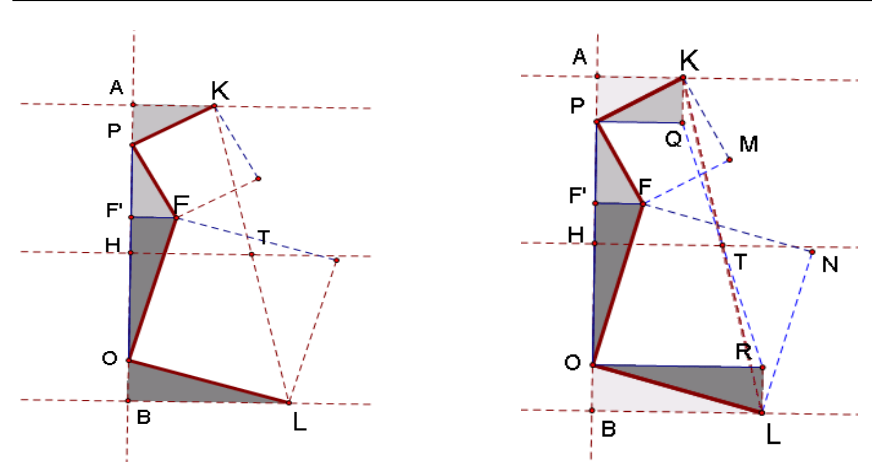

Fig. 23, 24. Screenshots of sequential diagrams of Vecten's theorem in Sketchpad

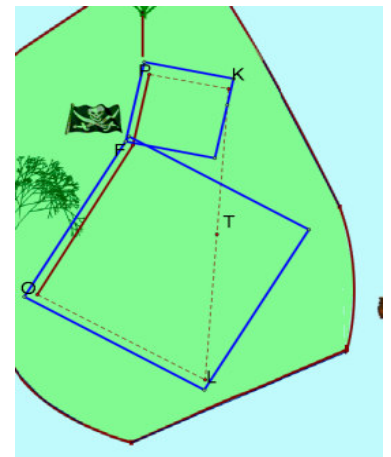

Fig. 25. Screenshot of Gamow's problem in Sketchpad

Mode A: The synthesis of the dynamic representation incorporates an image that is a permanently annotated pictorial representation, a two-dimensional hybrid object representing the closed and curved polygonal island, annotated in green and two dynamic fractal trees placed on the island. The background (font) of the screen has been selected to be light-blue using the complex preferences pop-up menu, to give the impression of the sea around the island. The positions of the trees $\mathrm{P}, \mathrm{O}$ are two points with zero degrees of freedom (Fig. 25). According to the Geometer's Sketchpad reference manual (2001) "points are the fundamental building blocks of classical geometry, and geometric figures such as lines and circles are defined in terms of points" (p.11). Hollebrands, Straeser and Laborde (2008, p.165) described the distinction between the three different kinds of points in a DGS environment: (a) a free point "can be directly dragged anywhere in the plane (degree of freedom 2)", (b) a point on an object "can be dragged only on this object (degree of freedom 1)" and (c) a constructed point "cannot be grasped and dragged (degree of freedom 0) but moves only if an element of which it is dependent is dragged". Point F, which represents the position of a moveable flag, can move with one degree of freedom and be dragged on screen. The rotation of the segments PF, FO to 90 degrees reorganizes the visual mathematical representations. Two new objects the segments PK, OL have been added on screen, the images of the PF, FO respectively. Point T (the treasure point), is the midpoint of the segment KL. It has constructed with zero degrees of freedom due to its dependence on the points $\mathrm{K}, \mathrm{L}$.

When students interact with the hybrid-dynamic diagram to create the rotations they interact with the intermediate representation of the pop-up menu for the selection of the rotation angle. The students can construct during instrumental genesis an instrumented action scheme of the perpendicularity and the congruence of the segments (PF and PK, OF and OL). The synthesis of the diagram leads to the following complex transformations (Patsiomitou, 2008a, 2012a):

- Rotation of the segments PF, FO to construct the points K, L (Fig. 26, 27, 28). This portrays a rearrangement of the visual representation giving the students the opportunity to perceive the internal relations between the mathematical objects on screen. Point $F$ can be dragged. This results in the transformation of the rotated segments, a complex transformation of the dragging and rotation of a geometric object.

- The hide-show action button for the points K, L, T also creates also a decomposition of the diagram. Concretely, an action button hides the point where the flag is located. The dependent objects have also been hidden (Fig. 27).

- The dragging of KL on the screen creates traces of the segment, meaning a set of points through which the segment passes. In this case (Fig. 28,29) the result is a complex transformation of the dragging and tracing of a geometric object (for example a point, a segment, or a line etc).
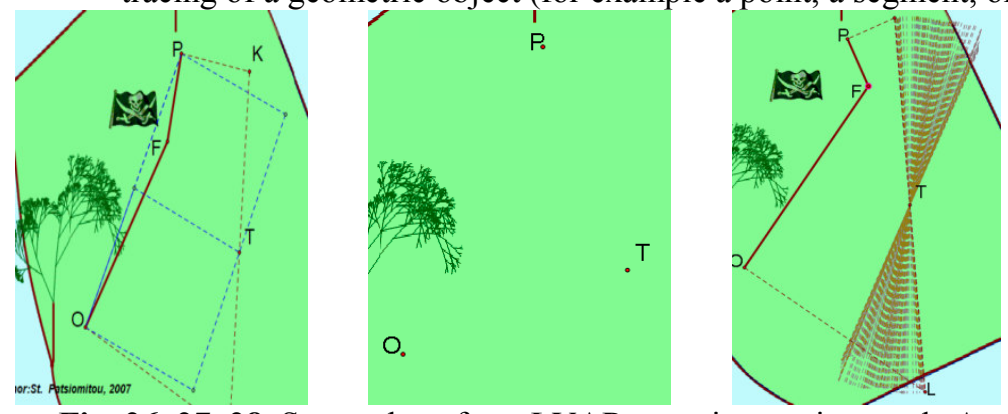

Fig. 26, 27, 28. Screenshots from LVAR experimentation mode A (before or after hiding the flag) in Sketchpad
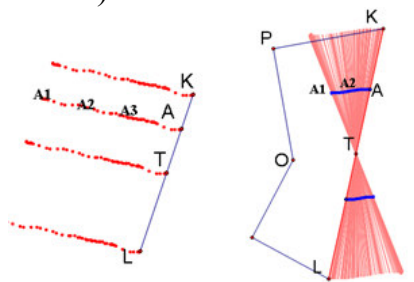

Fig. 29. Screenshot of the combination of tracing \& dragging the segment KL in Sketchpad 
Subsequently, the images of KL (Fig. 29) demonstrate the temporal positions of the segment as a correspondence of a point with its image. Every point of the initial constructed image has its correspondent image. Subsequently, we have a function $f$ which corresponds to every point $A$ on the segment KL to a point $f(A)$ the image of point A, where the point A corresponds to point A1 to point A2, and then to point An with the ndragging. We can thus see that the transformation of Point $A$ is a 1-1 function to every dragging depended of the previous point-image. The set of ' $A$ ' images on screen created by the trace command is the set of points through which Point A passes. A point's dragging on screen results to the transformation of its position and simultaneously the appearance of tracing tracks on screen, which show the path that the point follows or the tracks that a line passes due to dragging transformations. This action results to the determination of a basic property of the diagram (or a property of the diagram that remain stable and unaltered) which cannot be directly perceived from the diagram. "Trace" according to Jahn (2002) "emphasizes a dynamic interpretation of the representation of a trajectory of a point ... representing, at least implicitly, the image of a set of points for a certain application." (p. 79).

Mode C started with a second problem, investigated by the students in a paper-pencil environment (using a reformulated RGNA problem) reported in Patsiomitou (2008a, p. 372):

"An archaeologist has an old map which explains the position of a clay pot: You walk directly from point $\mathrm{P}$ to point $\mathrm{F}$ (F, E are constant points) counting your paces as you go. Then turn right 90 degrees and walk the same number of paces from point $F$. When you reach the end, put a stick in the ground. Return to point $P$ and walk directly to point $E$, again counting your paces and turning left 90 degrees and walking the same number of paces. Put another stick in the ground. The vessel (point V) is buried in the middle of the distance of the two sticks. Rejecting the procedure described above, the archaeologist did the following: starting from the midpoint of the segment FE, he followed the directions given on the map until he finally found the pot. a) Can you plot the shape according to the steps that archaeologist followed? And b) can you explain (using formal logic) why he was right?" (Fig. 30).

This is a complex phase. The dynamic diagrams are linked, using a translation transformation and every diagram on the right is a sequential successive and gradual procedure conducted on the previous one which is on the left. The translation gives to the dynamic representation the property to a simultaneous alteration of every dynamic object on them if we drag any point. The synthesis of the dynamic LVARepresentation has the following design: Point $\mathrm{F}$ has two degrees of freedom and point $\mathrm{O}$ has 0 degrees of freedom. The screen background has been changed using Sketchpad's complex preferences dialogue in order to link it to the previous page. The experimental dragging of point $\mathrm{V}$ does not transform the rectangle's figure, which remains a hybrid object on screen. In order to solve the problem we have to follow the following analysis: we have to prove that $\mathrm{V}$ is the midpoint of $\mathrm{KL}$, meaning we have to prove that $\mathrm{KL}$ and $\mathrm{AB}$ are dichotomized, or $\mathrm{KA} / /=\mathrm{BL}$ (Patsiomitou, 2008a, p.373).

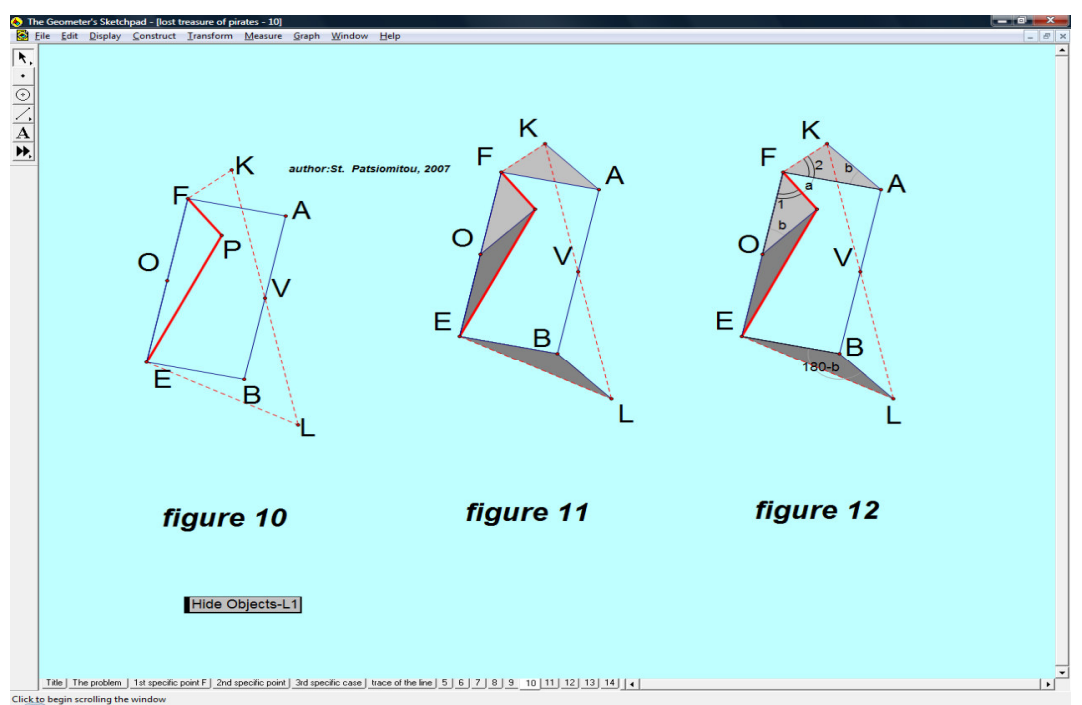

Fig. 30. Screenshot of Gamow's problem -Mode C (Patsiomitou, 2008a, p. 373)

The transformations of the triangles are intrinsically dynamic, but we can visualize only the result of the transformations on screen.

\section{Discussion: suggested investigational levels for students problem solving}

Stoyanova (1997) identified (a) free situations, (b) semi-structured situations and (c) structured situations to improve students' problem posing and problem solving in a range of classroom contexts. Christou, Mousoulides, Pittalis, Pitta-Pantazi, \& Sriraman (2005) in their work "An Empirical Taxonomy of Problem Posing Processes" 
also identified a theoretical model of problem posing as follows: "editing quantitative information, their meanings or relationships, selecting quantitative information, comprehending and organizing quantitative information by giving it meaning or creating relations between provided information, and translating quantitative information from one form to another" (p. 149).

I would argue that investigational activity of problem solving in a DGS, prompts the students to develop more reflective ways of thinking and the teacher to describe the problem in a way, which might be more interesting than in traditional approaches. Moreover, a teacher's intention for his/her students to learn through problem solving investigational process is associated in the words of Tony Brown, (1994) with the "presupposition about that to be learnt and learning is in a sense revisiting that already presupposed" (p.148). Tall (2004) used a metaphor of a "traveler" to explain how "different individuals may develop substantially different paths on their own cognitive journey of personal mathematical growth". As he argues:

"As an individual travels [...], various obstacles occur on the way that require earlier ideas to be reconsidered and reconstructed, so that the journey is not the same for each traveler. On the contrary, different individuals handle the various obstacles in different ways that lead to a variety of personal developments, some of which allow the individual to progress through increasing sophistication in a meaningful way while others lead to alternative conceptions, or even failure" (Tall, 2004, p. 286).

Battista (2011) also in his work "Conceptualizations and Issues related to Learning Progressions, Learning Trajectories, and Levels of Sophistication" defines the theoretical construct of "level of sophistication" in the following paragraph, through which he characterized students' development of conceptualizations and reasoning: "Clements and Battista (1992) described the difference between researchers' use of the terms stage and level as follows. A stage is a substantive period of time in which a particular type of cognition occurs across a variety of domains (as with Piagetian stages of cognitive development). In contrast, a level is a period of time in which a distinct type of cognition occurs for a specific domain (but the size of the domain may be an issue). Battista defines a third construct - a level of sophistication in student reasoning as a qualitatively distinct type of cognition that occurs within a hierarchy of cognition levels for a specific domain" (Battista, 2011, p.517).

In my opinion, the teacher's investigational activity in relation to the problem posed has to be implemented at several levels of sophistication, if a teacher is to help his/her students to develop deeper understanding and coherent reasoning.

- The first level is that of open problems using materials (e.g., squared papers, dot papers, or several means, including DGS). This phase can be extended by means of DGNA problems using sequential dynamic LVAR representations. When a student is engaged with the activity of solving a problem modeled by dynamic LVARepresentations $\mathrm{s} / \mathrm{he}$ connects that activity with both the product and the thought process during investigational process. LVARs scaffold students' mental processes such as perception, information recall and reasoning. Students can also discover the solution through active experimentation.

- The second level comes after the introduction of "big ideas" or "core ideas" (Battista, 2011). During this phase, the teacher can use DGGA problems posed for investigation and proof in a DGS environment. The students can mentally combine structural properties of conceived cognitive processes.

- The third level is that of real world HGNA problems which are modeled in a DGS environment using dynamic or hybrid-dynamic representations. A teacher can support students' reasoning by giving them other immediate problems which will scaffold the theoretical background required by the problem as they investigate all the possible or multiple solutions to the problem. They can also investigate a concrete situation of the hybrid-dynamic representations, choosing to give to the parameters concrete magnitudes.

- The forth level will be that of RGNA problems, accepting a challenge and trying to reinvent the solution. The students at this level must have the conceptual and procedural competence to investigate the problem. At this level, the problem cannot be solved by some routine procedures.

- The fifth level will be that of the problem in a SGGA problem in a static environment. This is the level with the higher degree of difficulty. This is why students are not able to solve static geometry problems, when they belong at the lower van Hiele levels.

According to Battista (2011) 'Selecting/creating instructional tasks, adapting instruction to students' needs, [...] require detailed, cognition-based knowledge of how students construct meanings for the specific mathematical topics targeted by instruction" (p.527).

This article contributes to the didactics of mathematics in the sphere of geometrical problem-solving. It was my aim to construct a model in which every subsequent problem in the specific didactic sequence proposed in the article would constitute the next level in the development of the students' reasoning.

For the student, solving a problem like Gramow's is like embarking on a journey into the unknown. They will meet conceptual obstacles along the way, and hence all manner of difficulties, but the benefits gained make the journey more than worthwhile, as the students emerges stronger from the experience. This is why 
mathematics educators need to take it on board that the journey is more important than the destination; that it is the process by which students arrive at an answer and the added sophistication they gain in their problem-solving, that raises their van Hiele level.

\section{Acknowledgments}

Particular thanks to my teachers on the Interuniversity "Didactics and Methodology of Mathematics" Postgraduate Program offered jointly by the National and Kapodistrian University of Athens and the University of Cyprus" (during the 2004-05 academic year) - my need to be constantly introducing and investigating new approaches in mathematics, following my own personal journey to knowledge, is largely due to my studies on this course. I dedicate this article to them.

\section{References}

Ainsworth, S. (1999). The functions of multiple representations. Computers \& Education, 33, 131-152.

Aamodt, A. (1991) A Knowledge-Intensive, Integrated Approach to Problem Solving and Sustained Learning, Knowledge Engineering and Image Processing Group. University of Trondheim. Norwegian Institute of Technology.

Arsac, G., Germain, G. \& Mante, M. (1988). Problème ouvert et situation-problème, IREM, Villeurbanne.

Atkinson, R. C. \& Shiffrin, R. M. (1968). Human memory: A proposed system and its control processes. In K. W. Spence \& J. T. Spence (Eds.), The Psychology of Learning and Motivation. USA: Academic Press.

Battista, M. (2011). Conceptualizations and issues related to learning progressions, learning trajectories, and levels of sophistication. The Mathematics Enthusiast, 8(3), 507-570.

Bell, A. (1976). A study of pupils' proof-explanations in mathematical situations. Educational Studies in Mathematics, 7, 23-40.

Bower, G.H., (1975) 'Cognitive psychology: an introduction'. In: W.K. Estes (ed.), Handbook of learning and cognitive processes, Vol. I. Introduction to concepts and issues. Hillsdale, NJ: Erlbaum. pp. 25-80.

Brown, T. (1994). Towards a hermeneutical understanding of mathematics and mathematical learning. In P. Ernest (Ed.), Studies in mathematics education (pp. 141-150). London: The Falmer Press.

Burger, W. F., \& Shaughnessy, J. M. (1986). Characterizing the van Hiele levels of development in geometry. Journal for Research in Mathematics Education, 17, 31-48.

Cerulli, M. (2004): Introducing pupils to algebra as a theory: L'Algebrista as an instrument of semiotic mediation. PhD Thesis, Dipartimento di Matematica, Università degli Studi di Pisa

Charles, R., \& Lester, F. (1982). Teaching problem solving: What, why \& how. Palo Alto, CA: Dale Seymour.

Chinnappan, M. (2006). Role of Digital Technologies in supporting Mathematics Teaching and Learning: rethinking the terrain in terms of schemas as epistemological Structures. . In C. Hoyles, J.-B. Lagrange, L. H. Son, and N. Sinclair (Eds.) Digital technologies and mathematics teaching and learning: Rethinking the terrain. Proceedings of the Seventeenth Study of the International Commission on Mathematics Instruction (pp. 98-104). Hanoi: University of Technology.

Christou, C., Mousoulides, N., Pittalis, M., \& Pitta-Pantazi, D. Sriraman, B. (2005) An Empirical Taxonomy of Problem Posing Processes. Zentralblatt für Didaktik der Mathematik, 37 (3), pp. 149-158

Clements, D. \& Sarama, J. (2014). Learning Trajectories: Foundations for Effective, Research -Based Education. In Maloney, A.P., Confrey, J.\& Nguyen, K.H. (Eds.) Learning over time: Learning Trajectories in mathematics Education. Charlotte: Information Age Publishers, pp. 1-29.

Cobb, P., Yackel, E., \& Wood, T. (1992). A constructivist alternative to the representational view of mind in mathematics education. Journal for Research in Mathematics Education, 23(1) 2-33.

de Villers, M. (1990). The role and function of proof in mathematics. Pythagoras, 24, 17- 24.

de Villiers, M. (1999). Mathematical treasure hunting. KZN Math Journal, 4(2), Nov, 23-28 and Proceedings of AMESA 2000, Univ. Free State, 271-276.

de Corte, E., Verschaffel, L., \& Greer, B. (2000). Connecting mathematics problem solving to the real world. In: Proceedings of the International Conference on Mathematics Education into the 21 st Century: Mathematics for living (pp. 66-73). Amman, Jordan: The National Center for Human Resource Development

Doerr, Helen M. and Pratt, Dave. (2008) "The learning of mathematics and mathematical modeling." In M. Kathleen Heid and Glendon W. Blume, eds. Research on technology and the teaching and learning of mathematics: Research syntheses. Information Age Publishing, pp. 259-285.

Drijvers, P. H. M. (1999). Students encountering obstacles using CAS: A developmental-research pilot study. In P. Kent, J. Monaghan, \& N. Zehavi (Eds.), Papers (Presentations, Reactions and Keynotes) of the CAME (Computer Algebra in Mathematics Education) meeting at the Weizmann Institute of Science, Rehovot, Israel, August 1-2, 1999 (pp. 34-49). Available online from http://metric.ma.ic.ac.uk/came/events/weizmann

Duval, R. (1999). Representation, vision and visualization: Cognitive functions in mathematical thinking. Basic 
issues for learning. In F. Hitt \& M. Santos (Eds.), Proceedings of the 21st Annual Meeting of the North American Chapter of the International Group for the Psychology of Mathematics Education, Volume 1 (pp. 3-26). Cuernavaca, Morelos, Mexico.

Fitzpatrick, R. (2007). Euclid's Elements of geometry. Morrisville, NC: Lulu.

Furinghetti, F. \& Paola, D. (2003). 'To produce conjectures and to prove them within a dynamic geometry environment: a case study', in N.A. Pateman, B.J. Dougherty, J.T. Zilliox (eds), Proc. of the joint meeting PME 27 and PMENA, v.2, 397-404 .https://files.eric.ed.gov/fulltext/ED500956.pdf

Fuys, D., Geddes, D., \& Tischler, R. (Eds). (1984). English translation of selected writings of Dina van HieleGeldof and Pierre M. van Hiele. Brooklyn: Brooklyn College. (ERIC Document Reproduction Service No. ED 287 697).

Freudenthal, H. (1971). Geometry between the devil and the deep sea. Educational Studies in Mathematics, 3(34), 413-435. Retrieved from http://www.springerlink.com/content/t43797147n37r585/fulltext.pdf

Freudenthal, H. (1973) Mathematics as an Educational Task (Dordrecht, The Netherlands: Reidel)

Gamow, G. (1948/1988). One, two, three--infinity. New York: Dover Publications. (Original work published 1947

Gravemeijer, K.P.E. (1994). 'Educational development and developmental research in mathematics education', Journal for Research in Mathematics Education 25(5), 443- 471.

Gravemeijer, K. P. E. (2004). Creating Opportunities for Students to Reinvent Mathematics. Paper presented at ICME 10, Kopenhagen, Denmark. July 4-11.

Gravemeijer, K., \& Terwel, J. (2000) Hans Freudenthal: a mathematician on didactics and curriculum theory. Journal of Curriculum Studies, 32(6), 777-796.

González G., Herbst P. (2009) Students' conceptions of congruency through the use of dynamic geometry software. International Journal of Computers for Mathematical Learning. 14 (2) 153-182.

Goldin, G., \& Janvier, C. (1998). Representations and the psychology of mathematics education. Journal of Mathematical Behavior, 17(1), 1-4.

Hanna, G. (1983). Some pedagogical aspects of proof. Interchange. 21(1), 6-13.

Hanna, G. \& Jahnke, H.N. (1993). Proof and application. Educational Studies in Mathematics, 24(4), 421-438.

Hollebrands, K., Laborde, C., \& StraBer, R. (2008). Technology and the learning of geometry at the secondary level. Research on Technology and the Teaching and Learning of Mathematics, 1, 155-205.

Isaksen SG. (1998) A review of brainstorming research: six critical issues for inquiry. Monograph 302, Creative Research Unit, Creative Problem Solving Group, Buffalo NY.

Jahn, A. P. (2002). "Locus" and "trace" in Cabri-géomètre: relationships between geometric and functional aspects in a study of transformations. Zentralblatt für Didaktik der Mathematik, 34(3), 78-84.

Jackiw, N. (1988). The Geometer's Sketchpad [Computer Software].Berkeley, CA: Key Curriculum Press

Kaput, J. J. (1989). Linking representations in the symbol systems of algebra. In S. Wagner \& C. Kieran, Research issues in the learning and teaching of algebra (pp. 167-194). Hillsdale, NJ: Erlbaum

Kaput, J. (1991). Notations and representations as mediators of constructive processes. In E. Glasersfeld (Ed.),Radical Constructivism in Mathematics Education (pp. 53-74). Netherlands: Kluwer Academic Publishers.

Karadag, Z. (2009). Analyzing students' mathematical thinking in technology -supported environments. PhD thesis. Department of Curriculum, Teaching and Learning Ontario Institute for the Studies in Education of the University of Toronto.

Krantz, S. G. (2007). The history and concept of mathematical proof. Downloaded from the Internet. http://www.math.wustl.edu/ sk/eolss.pdf

Dionysius Lardner (1855) "The first six books of the Elements of Euclid". Retrieved from https://www.maths.tcd.ie/ dwilkins/Courses/MA232A/MA232A_Mich2017/EuclidLardner 1855 TheFirstSixBooksOfTheElementsOfEuclid.pdf

Leron, U. \& $\overline{\text { Paz }}$, T. (2006). The slippery road from actions on objects to functions and variables. Proceedings of the 28th Conference of the International Group for the Psychology of Mathematics Education. Charles University. Prague, pp. 127-135. Retrieved from

https://homepages.warwick.ac.uk/staff/David.Tall/pdfs/festschrift.pdf

Lester, F., \& Kehle, P. (2003). From problem solving to modeling: The evolution of thinking about research on complex mathematical activity. In R. Lesh \& H. M. Doerr (Eds.), Beyond constructivism: Models and modeling perspectives on mathematics problem solving, learning and teaching (pp. 501-18). Mahwah, NJ: Lawrence Erlbaum Associates.

Lopez-Real, F., \& Leung, A. (2006). Dragging as a conceptual tool in dynamic geometry environments. International Journal of Mathematical Education in Science and Technology, 37(6), 665-679.

Mayer, R. E. (1983). Thinking, problem solving, cognition. New York: Freeman.

Mariotti, M. A. (2002). The influence of technological advances on students' mathematics learning. In L. D. 
English (Ed.), Handbook of international research in mathematics education (pp. 695-723). Mahwah, NJ: Lawrence Erlbaum.

Marrades, R., \& Guiterrez, A. (2000). Proofs produced by secondary school students learning geometry in a dynamic computer environment. Educational Studies in Mathematics, 44, 87-125.

Massaro, D. W., \& Cowan, N. (1993). Information processing models: Microscopes of the mind. Annual Review of the Psychology, 44, 383-425.

Newell, A. \& Simon, H. A. (1972). Human problem solving. New Jersey, USA: PrenticeHall.

Novak, J. D. (1990). Concept maps and vee diagrams: Two metacognitive tools for science and mathematics education. Instructional Science, 19, 29-52.

Nunokawa, K., \& Fukuzawa, T. (2002). Questions during problem solving with dynamic geometric software and understanding problem situations. Proceedings of the National Science Council, Republic of China, Part D: Mathematics, Science and Technology Education, 12(1), 31-43.

Osborn, Alex (1953). Applied Imagination: Principles and Procedures of Creative Problem Solving. New York, New York: Charles Scribner's Sons.

Patsiomitou, S. (2006): Transformations on mathematical objects through animation and trace of their dynamic parameters. Proceedings of the 5th Pan-Hellenic Conference with International Participation. Informatics and Education-ETPE, pp. 1070-1073, Thessaloniki, 5-8 October 2006. ISBN 960-88359-3-3. http://www.etpe.gr/custom/pdf/etpe1213.pdf

Patsiomitou, S., (2008a). The development of students' geometrical thinking through transformational processes and interaction techniques in a dynamic geometry environment. Issues in Informing Science and Information Technology journal. Vol.5 pp.353-393. Available on line http://iisit.org/IssuesVol5.htm

Patsiomitou, S. (2008b) Linking Visual Active Representations and the van Hiele model of geometrical thinking. In Yang, W-C, Majewski, M., Alwis T. and Klairiree, K. (Eds.) Proceedings of the $13^{\text {th }}$ Asian Conference in Technology in Mathematics. pp 163-178. Available on line http://atcm.mathandtech.org/EP2008/pages/regular.htm

Patsiomitou, S. (2008c) Custom tools and the iteration process as the referent point for the construction of meanings in a DGS environment. In Yang, W-C, Majewski, M., Alwis T. and Klairiree, K. (Eds.) Proceedings of the $13^{\text {th }}$ Asian Conference in Technology in Mathematics. pp. 179-192.Available on line http://atcm.mathandtech.org/EP2008/pages/regular.html

Patsiomitou, S. (2008d) Do geometrical constructions affect students algebraic expressions? In Yang, W., Majewski, M., Alwis T. and Klairiree, K. (Eds.) Proceedings of the $13^{\text {th }}$ Asian Conference in Technology in Mathematics. pp 193-202. ISBN 978-0-9821164-1-8. Bangkok, Thailand: Suan Shunanda Rajabhat University. Available on line http://atcm.mathandtech.org/EP2008/pages/regular.html

Patsiomitou, S. (2009a) Learning Mathematics with The Geometer's Sketchpad v4. Klidarithmos Publications. Volume B. ISBN: 978-960-461-309-0.

Patsiomitou, S. (2009b) The Impact of Structural Algebraic Units on Students' Algebraic Thinking in a DGS Environment. Electronic Journal of Mathematics and Technology (eJMT), 3(3), 243-260. ISSN 1933-2823.

Patsiomitou, S. (2010). Building LVAR (Linking Visual Active Representations) modes in a DGS environment at the Electronic Journal of Mathematics and Technology (eJMT), pp. 1-25, Issue 1, Vol. 4, February, 2010, ISSN1933-2823.

Patsiomitou, S. (2011) Theoretical dragging: A non-linguistic warrant leading to dynamic propositions. In Ubuz, B (Ed.). Proceedings of the 35th Conference of the International Group for the Psychology of Mathematics Education, Vol. 3, pp. 361-368. Ankara, Turkey: PME. ISBN 978-975-429-297-8

Patsiomitou, S. (2012a). The development of students' geometrical thinking through transformational processes and interaction techniques in a dynamic geometry environment. $\mathrm{PhD}$ thesis. University of Ioannina (December 2012).https://www.didaktorika.gr/eadd/handle/10442/35816

Patsiomitou, S. (2012b) A Linking Visual Active Representation DHLP for student's cognitive development. Global Journal of Computer Science and Technology, Vol. 12 Issue 6, March 2012. pp. 53-81. ISSN 9754350. Available at: http://computerresearch.org/index.php/computer/article/view/479/479

Patsiomitou, S. (2013) Students learning paths as 'dynamic encephalographs' of their cognitive development". International journal of computers \& technology [Online], 4(3) pp.802-806 (18 April 2013) ISSN 22773061

Patsiomitou, S. (2014). Student's Learning Progression Through Instrumental Decoding of Mathematical Ideas. Global Journal of Computer Science and Technology, Vol. 14 Issue 1,pp. 1-42. Online ISSN: 0975-4172.

http://computerresearch.org/index.php/computer/article/view/41/41

Patsiomitou, S. (2018a). A dynamic active learning trajectory for the construction of number pi $(\pi)$ : transforming mathematics education. International Journal of Education and Research. 6 (8) pp. 225-248.

Patsiomitou, S. (2018b). An 'alive' DGS tool for students' cognitive development. International Journal of Progressive Sciences and Technologies (IJPSAT) ISSN: 2509-0119. Vol. 11, No. 1. October 2018, pp. 35- 
54.

Pólya, G. (1966). How to solve it. New Jersey: Princeton University Press.

Szabo, A (2017). Mathematical abilities and mathematical memory during problem solving and some aspects of mathematics education for gifted pupils. PhD thesis. Department of Mathematics and Science Education. Stockholm University

Rabardel, P.(1995) Les hommes et les technologies - Approche cognitive des instruments contemporains. A. Colin, Paris

Scher, D. (2003). Dynamic visualization and proof: A new approach to a classic problem. The Mathematics Teacher, 96(6), 394.

Sedig, K., Rowhani, S., \& Liang, H. (2005). Designing interfaces that support formation of cognitive maps of transitional processes: An empirical study. Interacting with computers, 17(4), 419-452. Elsevier Science.

Sohma, K. (1997). Mathematics lessons using problem solving. Tokyo: Meiji Tosho. (in Japanese).

Stoyanova, E. N. (1997).Extending and exploring students' problem solving via problem posing. Retrieved from https://ro.ecu.edu.au/ theses/885.

Stamatis E. (1957) Euclid Geometry, Elements Books I, II, III, IV, O.E.D.B. , Athens

Sedig, K., \& Sumner, M. (2006). Characterizing interaction with visual mathematical representations. International Journal of Computers for Mathematical Learning, 11, 1-55. New York: Springer.

Simon, H. (1986). The information Processing Explanation of Gestalt Phenomena. Computers in Human Behavior, Vol.2. pp. 241-255.

Thiele, R. (2003). Antiquity. In: H.N. Jahnke (Eds.), A History of Analysis, pp. 1-40. American Mathematical Society. In Schiffer.

Toulmin, S.E. (1958). The uses of argument. Cambridge: Cambridge University Press.

Tall, D. (2004) Thinking Through Three Worlds of Mathematics, Proceedings of the 28th Conference of the international Group for the Psychology of Mathematics Education, Bergen, Norway, 4, pp.281-288.

Treffers A (1987) Three dimensions. A model of goal and theory description in mathematics instruction - the Wiskobas project. D. Reidel Publishing, Dordrecht

Van den Heuvel-Panhuizen, M.: 1996, Assessment and Realistic Mathematics Education, CD- $\beta$ Press Utrecht University, Utrecht, The Netherlands.

Varghese, T. (2017) "Proof, Proving and Mathematics Curriculum,"Transformations: 3 (1) https://nsuworks.nova.edu/transformations/vol3/iss1/3

Verillon, P. \& Andreucci, C. (2006). Artefacts and cognitive development: How do psychogenetic theories of intelligence help in understanding the influence of technical environments on the development of thought? In M. J. de Vries \& I. Mottier (Eds.), International handbook of technology education reviewing the past twenty years. Rotterdam: Sense Publisher

Wertheimer, M. (1985). A Gestalt perspective on computer simulations of cognitive processes. Computers in Human Behavior, I, 19-33.

[1] https://math.hawaii.edu/home/pdf/putnam/PolyaHowToSolveIt.pdf

[2] https://en.wikipedia.org/wiki/Euclidean_geometry\#Methods_of_proof).

[3] (http://users.ntua.gr/dimour/euclid/book1/postulate4.html)

[4] http://www.euclidraw.com 